Portland State University

PDXScholar

$11-2-1993$

\title{
Modeling of the Surface Plasmon Resonance (SPR) Effect for a Metal-Semiconductor (M-S) Junction at Elevated Temperatures
}

Erik De Jesus Sanchez

Portland State University

Follow this and additional works at: https://pdxscholar.library.pdx.edu/open_access_etds

Part of the Physics Commons

Let us know how access to this document benefits you.

Recommended Citation

Sanchez, Erik De Jesus, "Modeling of the Surface Plasmon Resonance (SPR) Effect for a MetalSemiconductor (M-S) Junction at Elevated Temperatures" (1993). Dissertations and Theses. Paper 4624. https://doi.org/10.15760/etd.6508

This Thesis is brought to you for free and open access. It has been accepted for inclusion in Dissertations and Theses by an authorized administrator of PDXScholar. Please contact us if we can make this document more accessible: pdxscholar@pdx.edu. 
AN ABSTRACT OF THE THESIS OF Erik De Jesus Sánchez for the Master of Science in Physics presented November 2, 1993.

Title: Modeling of the Surface Plasmon Resonance (SPR) Effect for a MetalSemiconductor (M-S) Junction at Elevated Temperatures.

\section{APPROVED BY THE MEMBERS OF THE THESIS COMMITTEE:}

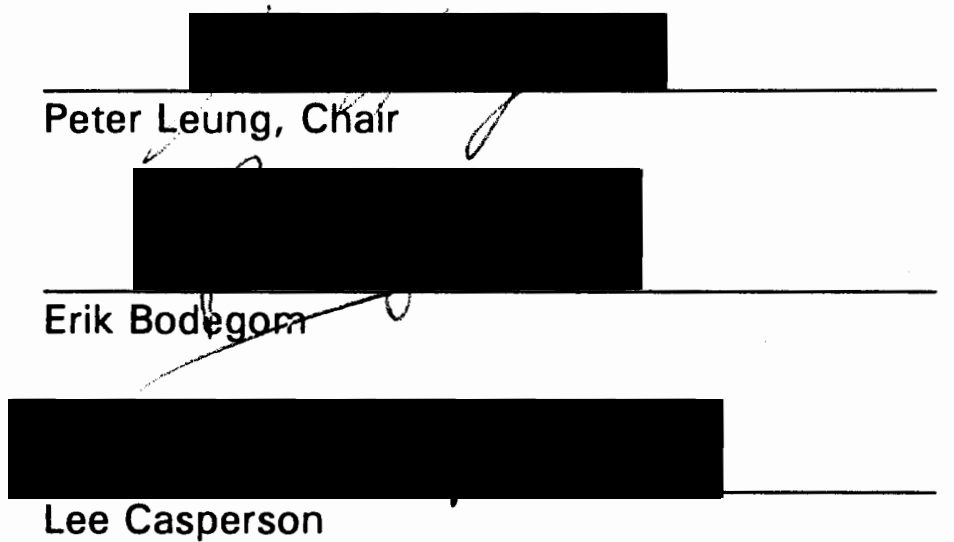

The effect of temperature increase on the optical excitation of Surface Plasmon Resonance (SPR) at an Ag-Si metal-semiconductor (M-S) junction at a wavelength of $1.152 \mu \mathrm{m}$ is investigated theoretically using computer modeling in Fortran. In order to accurately quantify the SPR, the temperature dependent optical constants for $\mathrm{Ag}$ and $\mathrm{Si}$ are obtained theoretically or semiempirically, using a Drude model for $\mathrm{Ag}$ and previous experimentally 
determined equations for $\mathrm{Si}$ (the behavior of the optical constants for crystalline Si and doped Si are found to have very little deviation between each other for our case). An improvement in the theoretical derivation for the optical constants of $\mathrm{Ag}$ is obtained, maintaining self-consistency. The optical constants are utilized to quantify the reflectance of an incident wave on an M-S junction, using Fresnel equations for a four layer system. The reflectivity of the M-S junction is indicative of the surface plasmon generation. There exists much industrial interest in increasing the amount of photocurrent generation in semiconductors for a given number of incident photons. This increase in photocurrent is often referred to as enhancing the quantum efficiency (Q). It has been previously shown by many groups that there can be an appreciable enhancement of $Q$ due to the optical excitation of surface plasmons on a Schottky barrier junction (M-S junction), although all these previous studies were done at room temperature. Hence, the studies of temperature effect of SPR at the M-S junction could lead to interesting effects for the $Q$ as well. In this thesis, we have studied qualitatively the effect of temperature increase on the optical excitation of SPR at an Ag-Si junction. From these results we have attempted to draw inference to the possibility of the enhancement of $Q$ at elevated temperatures for such a diode junction. 
MODELING OF THE SURFACE PLASMON RESONANCE (SPR) EFFECT FOR

A METAL-SEMICONDUCTOR (M-S) JUNCTION AT ELEVATED

TEMPERATURES

by
ERIK DE JESUS SÁNCHEZ

A thesis submitted in partial fulfillment of the requirements for the degree of

\section{MASTER OF SCIENCE}

in

PHYSICS

Portland State University

1993 


\section{TO THE OFFICE OF GRADUATE STUDIES:}

The members of the Committee approve the thesis of Erik de Jesus Sánchez presented November 2, 1993.
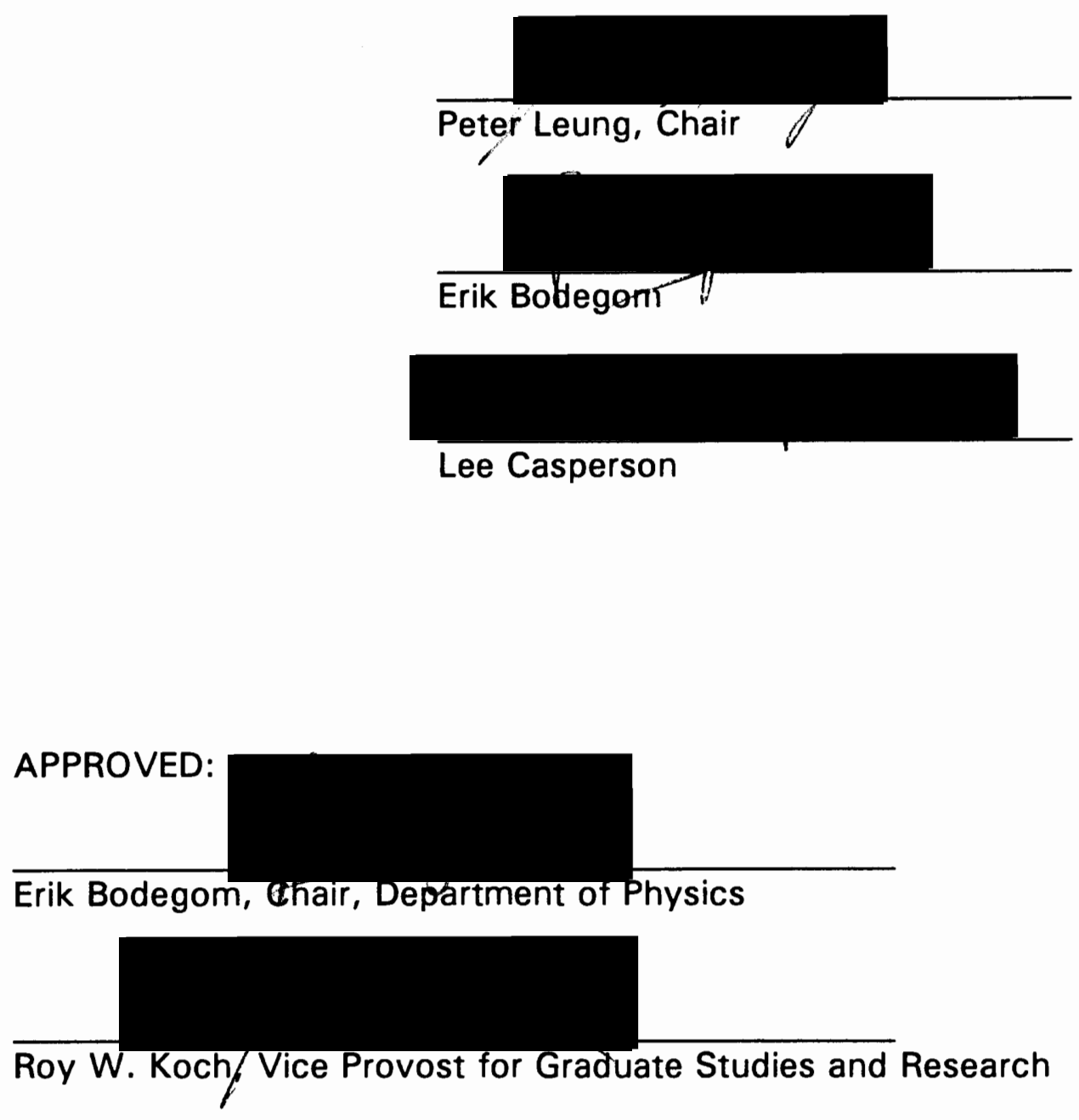


\section{ACKNOWLEDGEMENTS}

This work would have never been possible without the support from many people. It is my pleasure at this time to give proper credit to these people.

With deep gratitude I would like to thank my family and friends, who were all extremely supportive during the writing of this thesis. My parents deserve much credit for their unending support towards my educational endeavors. I would like to thank my friends for their understanding of spending more time writing this thesis than with them.

I am especially grateful to my thesis advisor, Professor Peter T. Leung for his constant support and willingness to explain the theoretical aspects of this work. Without his tenacity this thesis would have taken much longer to finish. 
TABLE OF CONTENTS

PAGE

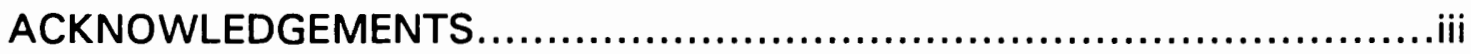

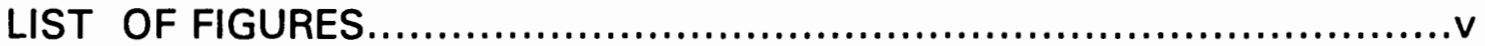

CHAPTER

I INTRODUCTION..................................................

II OVERVIEW OF SURFACE PLASMON RESONANCE

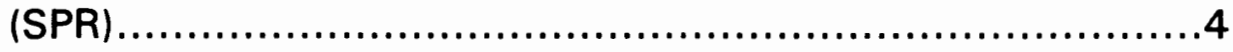

III OVERVIEW OF PREVIOUS STUDIES OF THE SPR EFFECT FOR A SCHOTTKY-BARRIER .................................12

I V OPTICAL CONSTANTS FOR SILVER (Ag) AND SILICON (Si) AT ELEVATED TEMPERATURES.............................17

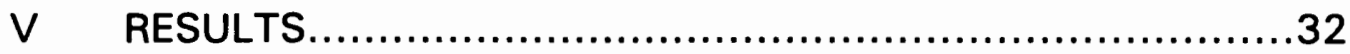

V I DISCUSSION AND CONCLUSION.............................54

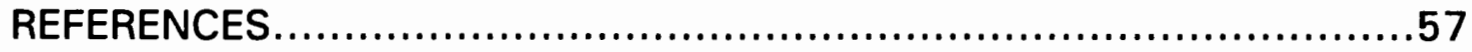

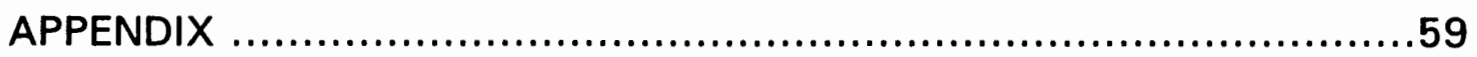




\section{LIST OF FIGURES}

FIGURE

PAGE

1. Collective Oscillations of the electrons at an interface.....5

2. Dispersion Relations.....................................

3. Basic ATR Geometries..................................9

4 Our Kretschmann Geometry for Glass, Ag, and Si........10

5. Energy gap levels for an M-S junction.....................14

6. Index of refraction for fused-silica as a function of

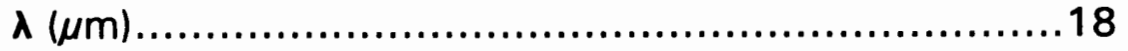

7. Real index of refraction for $\mathrm{Ag}$ as a function of

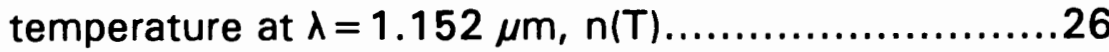

8. Imaginary index of refraction (extinction coefficient) for $\mathrm{Ag}$ as a function of temperature at

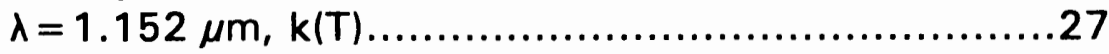

9. Real index of refraction for $\mathrm{Si}$ as a function of temperature at $\lambda=1.152 \mu \mathrm{m}, \mathrm{n}(\mathrm{T}) \ldots \ldots \ldots \ldots \ldots \ldots \ldots \ldots . .28$

10. Extinction coefficient for $\mathrm{Si}$ as a function of temperature at $\lambda=1.152 \mu \mathrm{m}, k(T)$. Note the semilog scale used.....................................29

11. Optimum Ag SPR dip occurrence at $40 \mathrm{~nm}$ thickness.........................................34 
12. SPR curves for 0 to $50 \mathrm{~nm}$ Si on a $40 \mathrm{~nm}$ layer of $\mathbf{A g}$

13. SPR and Waveguide mode resonant dip angles versus Si.

14. SPR dip angle at elevated temperatures on a 0 to $53 \mathrm{~nm}$ Si thickness.

15. SPR dip angle at elevated temperatures on a 0 to $53 \mathrm{~nm}$ Si thickness w/ Heated glass effect.

16. SPR reflectivity at elevated temperatures -

$\mathrm{Ag}(40 \mathrm{~nm})$ only

17. Change of SPR reflectivity $(\triangle R)$ at elevated temperatures - Ag (40 nm) only.

18. SPR $\triangle R$ at SPR angle $\left(44.18^{\circ}\right)$ at elevated temperatures - Ag (40 nm) only.

19. SPR $\triangle R$ at elevated temperatures -

Ag $(40 \mathrm{~nm})$ only, w/ Heated glass effect

20. SPR reflectivity at elevated temperatures -

$\mathrm{Ag}(40 \mathrm{~nm})$ \& Si $(30 \mathrm{~nm})$.

21. SPR $\triangle R$ at elevated temperatures -

Ag $(40 \mathrm{~nm}) \& \mathrm{Si}(30 \mathrm{~nm})$.

22. SPR $\triangle R$ at SPR angle $\left(48.85^{\circ}\right)$ at elevated temperatures - Ag $(40 \mathrm{~nm})$ \& Si $(30 \mathrm{~nm})$

23. SPR $\triangle R$ at elevated temperatures -

Ag $(40 \mathrm{~nm})$ \& Si $(30 \mathrm{~nm}) \mathrm{w} /$ Heated glass effect. 
24. SPR reflectivity at elevated temperatures -

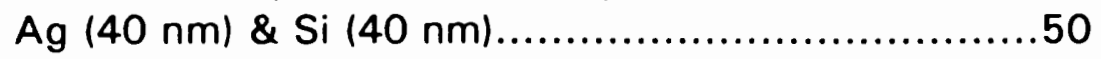

25. SPR $\triangle R$ at elevated temperatures -

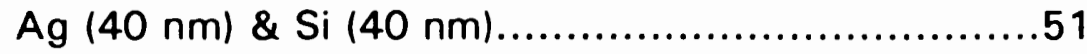

26. SPR $\triangle R$ at SPR angle $\left(56.20^{\circ}\right)$ at elevated temperatures - $\mathrm{Ag}(40 \mathrm{~nm}) \& \mathrm{Si}(40 \mathrm{~nm})$................52

27. SPR $\triangle R$ at elevated temperatures -

$\mathrm{Ag}(40 \mathrm{~nm}) \& \mathrm{Si}(40 \mathrm{~nm}) \mathrm{w} /$ Heated glass effect..........................................53 


\section{CHAPTER I}

\section{INTRODUCTION}

Over the past many years there has been much research performed in the field of interaction of optical waves with materials, both in the bulk material as well as at the surface. With the advent of diode lasers and charged coupled device (CCD) arrays (light detection with semiconductor junctions), the interaction of photons with thin films has become very important. When a photon is incident upon a material such as a metal, many very complex mechanisms occur which, in the past, have not been fully investigated. It is well known that when light reflects from a metal surface, reflection and to some degree, transmission of light occurs at the air - metal interface. Some time ago it was observed that this isn't always the case. With the proper arrangement almost no reflection or transmission of the light can occur. This seems contradictory to what one learns in a basic physics course; the energy cannot be "lost". It is only until recently that people have some theoretical understanding of the phenomena, which is known as surface plasmon resonance, or SPR. How SPR is optically generated will be discussed in the following chapter.

The SPR phenomena is only recently being commercially utilized. This 
effect is being used in many important areas, such as microbiology, material science, optics, and many other fields. In the biological field it is used as a biosensor, being used to detect pico-molar concentrations of antigens in solutions. In material science it is used in a unique arrangement to determine the thickness of metal thin films. In optics, the effect has the ability to enhance second harmonic generation, for example. Only recently has this affect been applied to the optoelectronic field of study where SPR has been found to dramatically increase the flow of electrons across a metalsemiconductor junction. This latter effect has many interesting applications, especially with the technological push for optical computers and increases in photonic efficiency.

When incident light has the affect of causing electrons to flow in a semiconductor, it generates a photocurrent. It has been previously shown by many groups that an increase in photocurrent generation will occur with the SPR effect applied to a an M-S junction. The ratio of photocurrent to incident photons is commonly known as quantum efficiency, or $Q$. The incident photons generate charge surface density waves at the Ag-Si interface which can boost electrons to cross the Schottky barrier. The surface waves are affected by many factors such as frequency $\omega$ of incident waves, thickness of the $\mathrm{Ag}$ and $\mathrm{Si}$ materials, and temperature $\mathrm{T}$, these factors can either enhance or diminish 0 . Although all these factors are important, we are primarily concerned with the temperature effect on the M-S junction relating 
to $Q$. One practical concern comes from at least the consideration that in certain practical circumstances these junctions will operate at elevated temperatures. So it is worthwhile that we study this affect and make some contribution to the subject.

In order to effectively model this thermal effect, we have to adopt a mechanism which would ensure the optical excitation of SPR. To accomplish the modeling, many factors such as optical constants, thermal expansion, incident wavelength, Fresnel optics and specific material geometries must be dealt with. The most complicated factor being the optical constants of metals and semiconductors. Thus, the organization of this thesis is as follows; first an overview of how SPR can be optically created will be presented, then the temperature-dependent optical constants will be derived, results of the theoretical modeling will be presented, and then some implications to the temperature effect of SPR on $Q$ will be made based on our results. 


\section{CHAPTER $\mid 1$}

\section{OVERVIEW OF SURFACE PLASMON RESONANCE (SPR)}

Surface plasmon resonance here refers to the collective resonant excitation of free electrons at a metal-dielectric interface. The first indirect discovery of SPR was from a phenomenon called Wood's anomaly discovered by Wood in 1935 while studying reflections from metallic gratings. It wasn't until 1957 that this phenomenon was predicted by Ritchie. Initial observation of SPR by Powell was via electron energy loss spectroscopy EELS. Today SPR could be excited by various optical methods such as Attenuated Total Reflection (ATR) technique. As mentioned before, SPR excitation has many applications such as monitoring thin film thickness, biosensing, enhancing second harmonic generation, light modulation and other sensing aspects. ${ }^{1}$ Recently, there also exists interest in enhancing sensitivity of the SPR effect for monitoring the temperature of thin films being heated by pulsed-lasers. ${ }^{2}$ In order to have a basic understanding of the concept of SPR effect, let us first refer to figure 1 . It is well known that the excitation of the SPR is accompanied by a wave propagating along the surface with the field being exponentially damped along the direction normal to the surface. The electromagnetic theory behind SPR is rather complex, but the general 
COLLECTIVE OSCILLATION OF FREE ELECTRONS

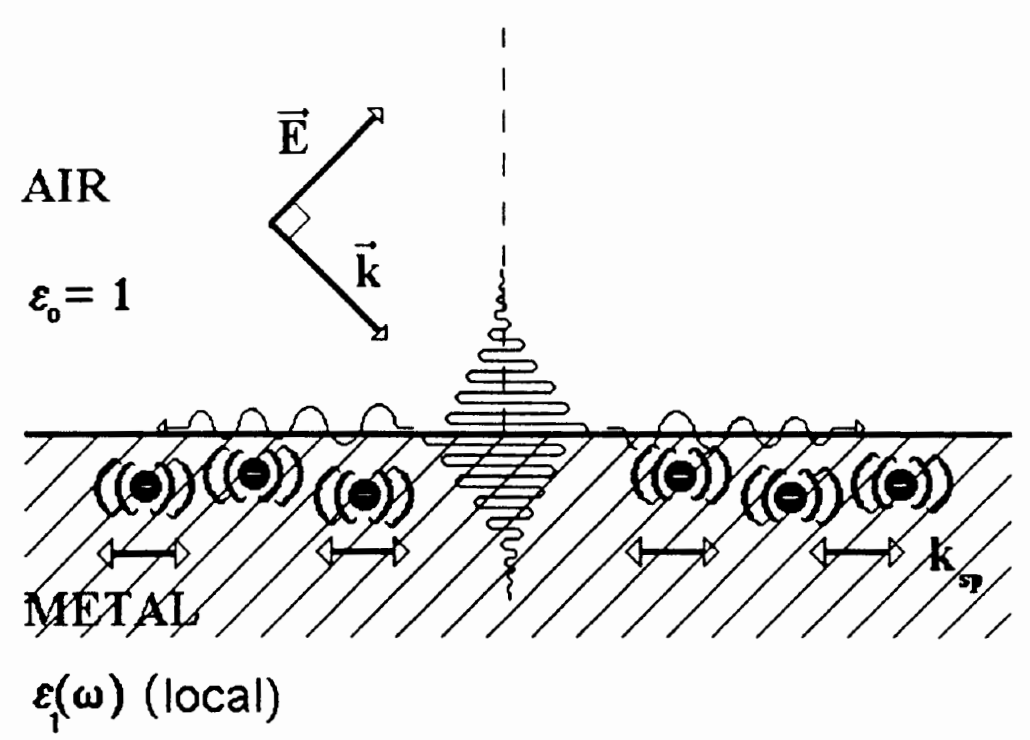

Figure 1. Collective oscillations of the electrons at an interface. 
phenomena can be easily explained. The criteria for SPR can be understood using Maxwell's equations with the appropriate boundary conditions applied. ${ }^{3}$

A p-polarized electromagnetic wave incident upon a conducting surface has a normal E-field component which is discontinous at the smooth interface (refer to figure 1). We would like for the discontinuity of the normal E-field component in the incident media to result in a collective oscillation of surface charge on the metal (refer to figure 1), where :

$$
\sigma=\epsilon_{1} E_{1}-\epsilon_{0} E_{0},
$$

with $\sigma$ the surface charge, $E_{0}$ the normal component in the first media and $E_{1}$ the normal component in the second media, $\epsilon_{0}$ the dielectric constant of the first layer and $\epsilon_{1}$ the metal's dielectric constant. However, the criteria for the collective oscillation of electrons (SPs) is not met by this arrangement. The dispersion relations of figure 2 a explain why this cannot occur. The surface plasmon polariton curve on the graph represents the true non-radiative SP wave we would like to generate. For an SP wave to be optically excited, a light line must intersect with the SP curve. Given the dispersion relation for an incident wave, a light line will have its wave vector along the surface $\left(k_{1}\right)$ given by:

$$
k_{1}=\frac{\omega}{c} \sqrt{\epsilon_{0}} \cdot \sin \theta_{1},
$$

with $\theta_{i}$ the incident angle, $\omega$ the optical frequency, $c$ the speed of light, $\epsilon_{0}$ the 

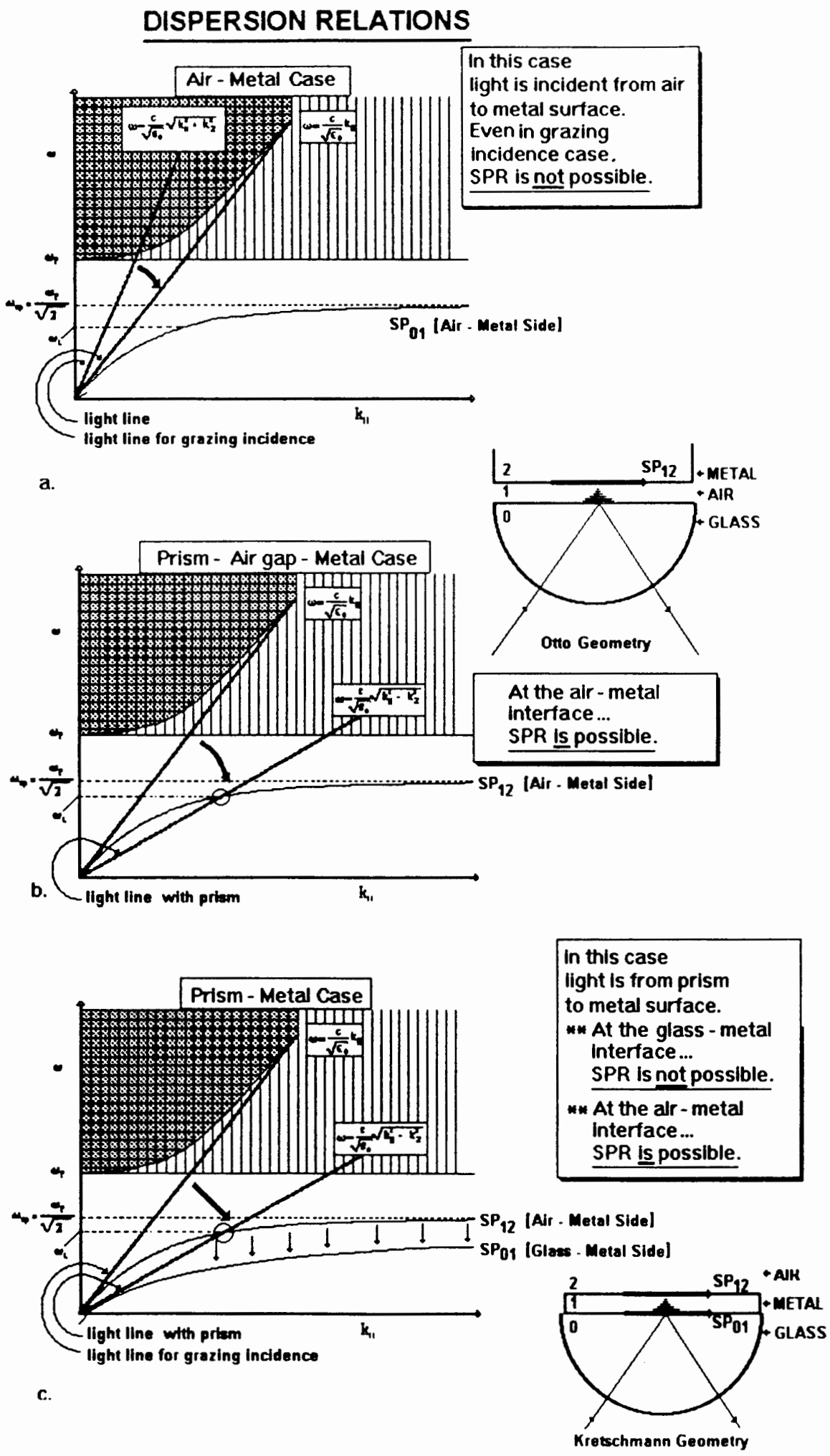

Figure 2. Dispersion Relations. 
dielectric constant of the incident medium.

On the other hand, it could be shown from Maxwell's equations that to excite a true (non-radiative) SP, one requires a wave vector along the surface to be given by:

$$
k_{s p}=\frac{\omega}{c} \sqrt{\frac{\varepsilon_{0} \varepsilon_{1}}{\varepsilon_{0}+\varepsilon_{1}}},
$$

For the excitation of $S P$, one requires $\varepsilon_{1}$ being negative and $\left|\epsilon_{1}\right|>\varepsilon_{0} .{ }^{4}$ One can see from [2.2] and [2.3] that, for a given $\omega$, we always have $k_{1}<$ $\omega / c(\epsilon)^{1 / 2}<k_{s p}$, which implies that the light line will never intersect the SP dispersion curve in that case. To excite a surface plasmon wave at an interface optically, the incident wave vector must have a parallel component that is equal to the surface-plasmon wave vector $\left(\mathrm{ie}, \boldsymbol{k}_{1}=k_{s p}\right)$, where $k_{s p}$ is given by [2.3]. This can be achieved optically by a couple of different geometries, such as Otto and Kretschmann arrangements. ${ }^{5}$ In this physical arrangement (refer to figure 1 and $3 a, b$ ) the SP is excited by an evanescent wave obtained from total reflection in the prism, the light line of this wave will then intersect the SP line since the wave vector component normal to the surface becomes imaginary (see Fig. $2 a, b$ ). For a given frequency $\omega$, this light line will intersect the SP dispersion curve at a certain angle $\theta_{\mathrm{sp}}$ at which the SP will be resonantly excited. In addition, it can be shown that this occurs when $\boldsymbol{\theta}_{\mathrm{sp}}$ is greater than the critical angle 
BASIC SPR SETUP ACCOROING TO THE ATR METHOD

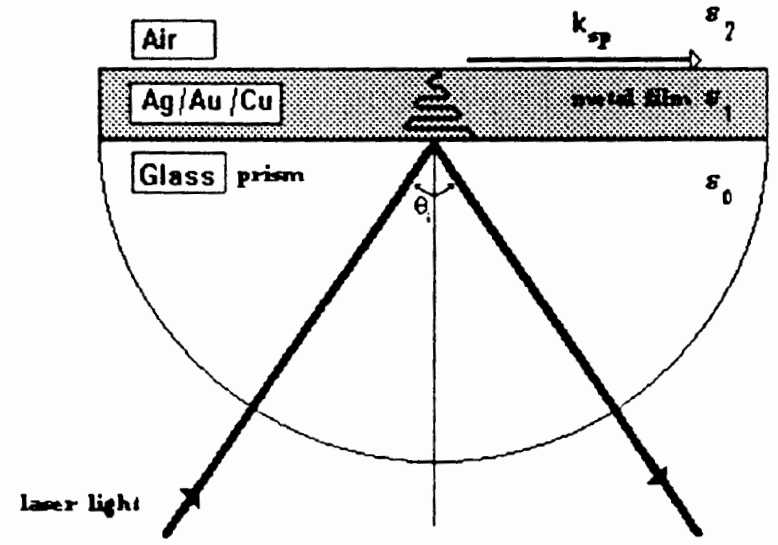

a. Kretschmann geometry.

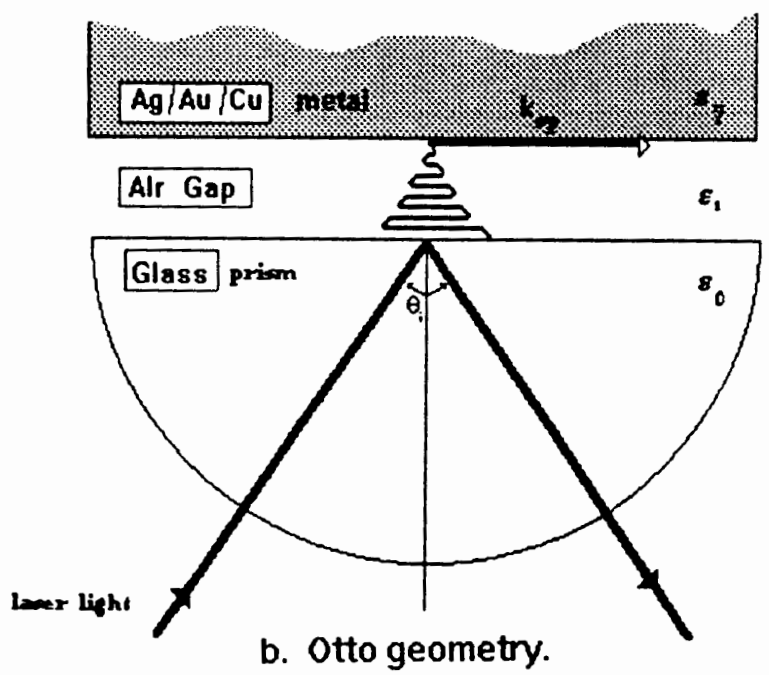

Figure 3. Basic ATR Geometries. 


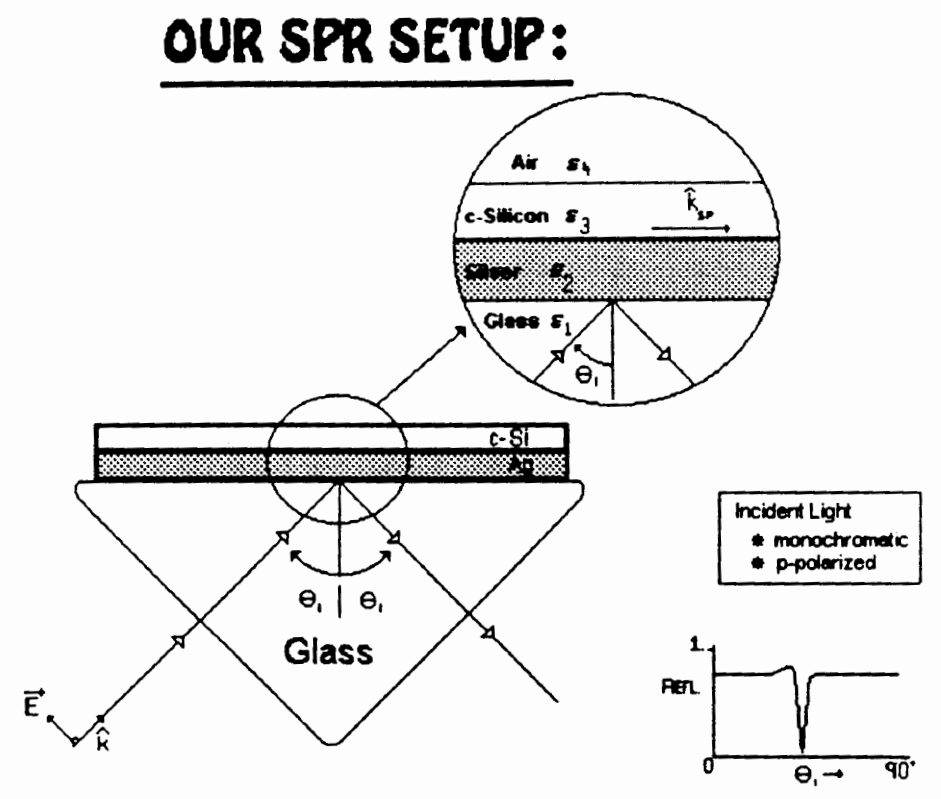

Figure 4. Our Kretschmann Geometry for Glass, $\mathrm{Ag}$, and Si. 


$$
\theta_{c}=\sin ^{-1}\left[\sqrt{\frac{1}{\varepsilon_{0}}}\right] \text {, }
$$

where $\epsilon_{0}$ here refers to the dielectric constant of the glass prism There are many factors which will affect the SPR. This paper deals with a set of fixed materials (fused silica, $\mathrm{Ag}, \mathrm{Si}$ and air (refer to Fig.4)) and fixed wavelength $(1.152 \mu \mathrm{m})$. The only variables are the layer thicknesses, angle of incidence, and temperature. 


\section{CHAPTER I I}

\section{OVERVIEW OF PREVIOUS STUDIES OF THE SPR EFFECT FOR A SCHOTTKY-BARRIER}

Surface plasmons have been found to enhance the $Q$ of a Schottky barrier system. The concept of $\mathrm{Q}$ is often generally described as the average ratio of photo-emmitted electrons to incident photons. Once the proper physical arrangement for the excitation of surface plasmon is created, then a direct correlation can be made between the reflectance dip at the SP angle and the Q. Arrangements often used for enhancing $\mathrm{Q}$ incorporate both the Kretschmann and Otto ATR geometries. ${ }^{6.7}$ The incident photon energy must be of a specific type of wave and certain conditions must be met before photocurrent is generated. The Kretschmann system provides the necessary type of wave so this occurs. It has been observed that up to approximately an 11-fold enhancement can be achieved when SPR is excited. ${ }^{8}$ In the ATR approach, the excitation of a surface plasmon is detected by a minimum in the reflectance at some specific angle. At the minimum, p-polarized incident photons are transformed into SPs at the metal dielectric interface. The metaldielectric junction we have chosen is a Ag-Si Schottky bilayer. At this junction the SPs excite electrons which can be emitted from the silver into the depletion 
region of the Si through the barrier, provided the photon energy absorbed by the electrons is greater than the barrier height. As photocurrent increases, an increase in the $Q$ results. In the present work we quantify how an increase in the temperature of a Schottky barrier system will affect the excitation of SPs at the Ag-Si junction. If the SP generation is affected by temperature increase then it may follow that the photocurrent (hence $\mathrm{Q}$ ) is affected. As mentioned before, people have found both theoretically as well as experimentally that SP generation, being a result of many factors, directly enhances $Q$. However, all these previous studies were done at room temperature and our work here examines the temperature effect on the 0 .

The $\mathrm{Q}$ of an n-type Schottky barrier (Au-GaAs) has been theoretically and experimentally modeled at room temperature (without a bias voltage applied) by a group at Cambridge. ${ }^{6}$ A main interest of this group was to determine the metal layer thickness for maximum SP excitation, using the Kretschmann geometry. They found the optimum thickness for a Au layer is $40 \mathrm{~nm}$, close to what we have found here for $\mathrm{Ag}$ (it is important to mention that the optimum thickness' for SP generation of both $\mathrm{Ag}$ and $\mathrm{Si}$ as studied in our present work are somewhat thinner than commercially available products). The Cambridge group uses a different order of layering than the one we used in our modeling, they have the semiconductor layer in contact with the prism instead of the metal layer, which is opposite to ours. The advantage of having the metal layer next to the prism is that the SPs will be excited between the metal and the 


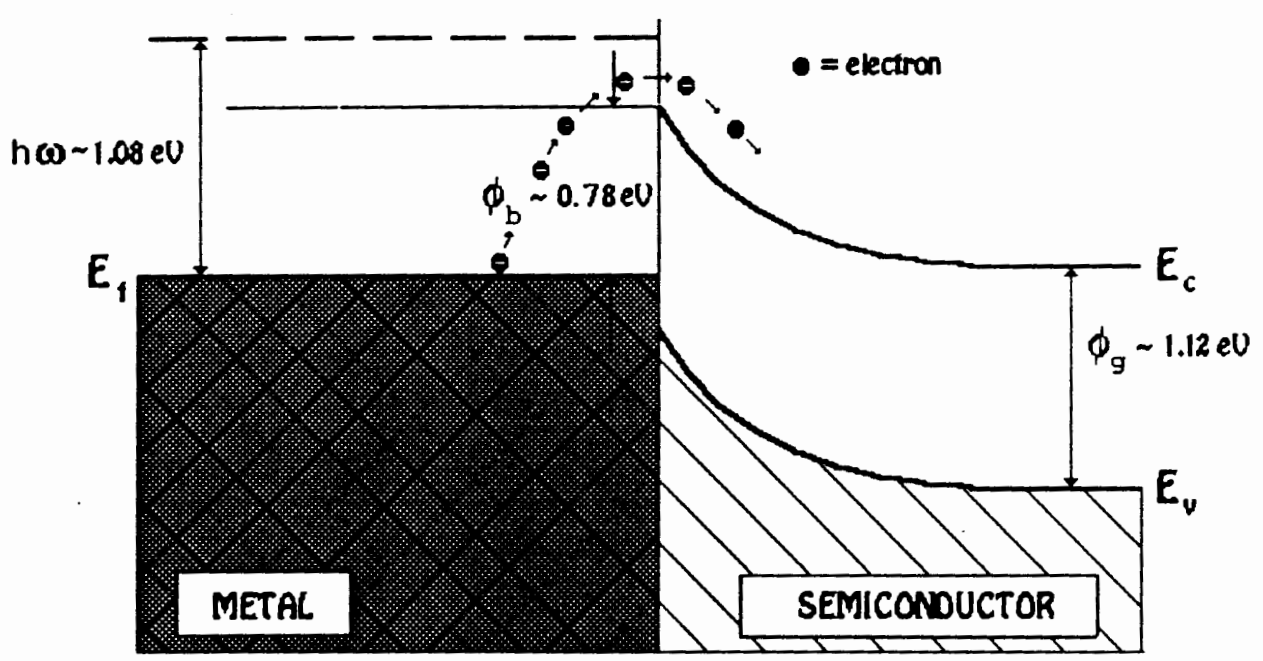

Silver and $n$ - type Silicon:

Figure 5. Energy gap levels for an M-S junction. 
semiconductor, whereas the other layering has its SPs generated at the metalair interface. Also, the energy barriers for the Au-GaAs system differs greatly from the Ag-Si system in that the GaAs energy gap is relatively much larger $(\cong 1.42 \mathrm{eV})$ than the incident photon energy used $(\cong 1.08 \mathrm{eV})$. The lower photon energies aren't likely to excite carriers in the semiconductor. Conversely, in our case, the Si band gap energy ( $\cong 1.12 \mathrm{eV})$ is very close to the incident photon energy $(\cong 1.08 \mathrm{eV})$. This leads to an interesting situation. As temperature is increased in our system the Si band gap energy lowers, this leads to the possibility that, at an elevated temperature, the photon energy could become greater than the band gap. As a result of this, electron-hole pairs are created within the Si. The results obtained by the Cambridge group were not surprising, they showed that just as the sharp SP dip occurs, the $Q$ makes a sharp peak. It is also not a surprise that the s-polarized case shows no $Q$ enhancement, since no discontinuity occurs in the E-field at the surface thereby not creating surface charges.

Another method which has been extensively studied is called the Otto geometry. ${ }^{5}$ In this system there is an air gap between the prism coupler and the metal-dielectric (fig. 3b). Like the Kretschmann geometry, the Otto arrangement makes it possible to excite SPs, in turn producing a photoemission current. A group at the University of Lowell has extensively studied the SP enhanced photoemission in Schottky diodes using the Otto geometry. ${ }^{7}$ Similar to the Cambridge group, a system of Al-GaAs in the Otto 
geometry had the same results as the Kretschmann geometry. It was found that as the SP excitation increases, the $Q$ increases. They found that the $Q$ was heavily dependent on factors such as the probability of the electron entering the semiconductor, metal film thickness, and the air gap thickness.

Since it has been shown both theoretically and experimentally that direct correlation between the degree of SP excitation is proportional to the $Q$, then it follows that any factor affecting SP excitation such as temperature will directly affect the $Q$. It will be shown that the temperature effect does have a significant influence on SP generation in our Ag-Si Schottky diode. 


\section{CHAPTER IV}

\section{OPTICAL CONSTANTS FOR SILVER (Ag) AND SILICON (Si) AT ELEVATED TEMPERATURES}

Vital information needed in our modeling using the Fresnel equations are the values (which may be complex) of the index of refraction for all the material layers. All layers in our system (except for air) require special attention. It is the value of the imaginary part of the complex index of refraction which indicates to what degree the incident wave is absorbed (attenuated) and the value is of great importance to the SPR phenomenon.

The first layer in our equations is the glass prism, which we are assuming to be UV synthetic fused silica (amorphous silicon dioxide) with an index of refraction given by I.H. Malitson, ${ }^{9}$

$$
n^{2}-1=\frac{\left(.6961663 \lambda^{2}\right)}{\left(\lambda^{2}-(0.0684043)^{2}\right)}+\frac{\left(0.4079426 \lambda^{2}\right)}{\left(\lambda^{2}-(0.1162414)^{2}\right)}+\frac{\left(0.8974794 \lambda^{2}\right)}{\left(\lambda^{2}-(9.896161)^{2}\right)}
$$

For $\lambda=1.152 \mu \mathrm{m}$, we obtain $n_{0}=1.448$ (refer to figure 6 ). The real index experiences a very small change due to an increase in temperature of $1.28 \times 10^{-5} /{ }^{\circ} \mathrm{C}$ (for 0 to $700^{\circ} \mathrm{C}$ ). Although this real index change has no significant effect on the SPR results, some graphs shown later will illustrate the change in SPR with a heated glass effect taken into account. 
FUSED SILICA INDEX

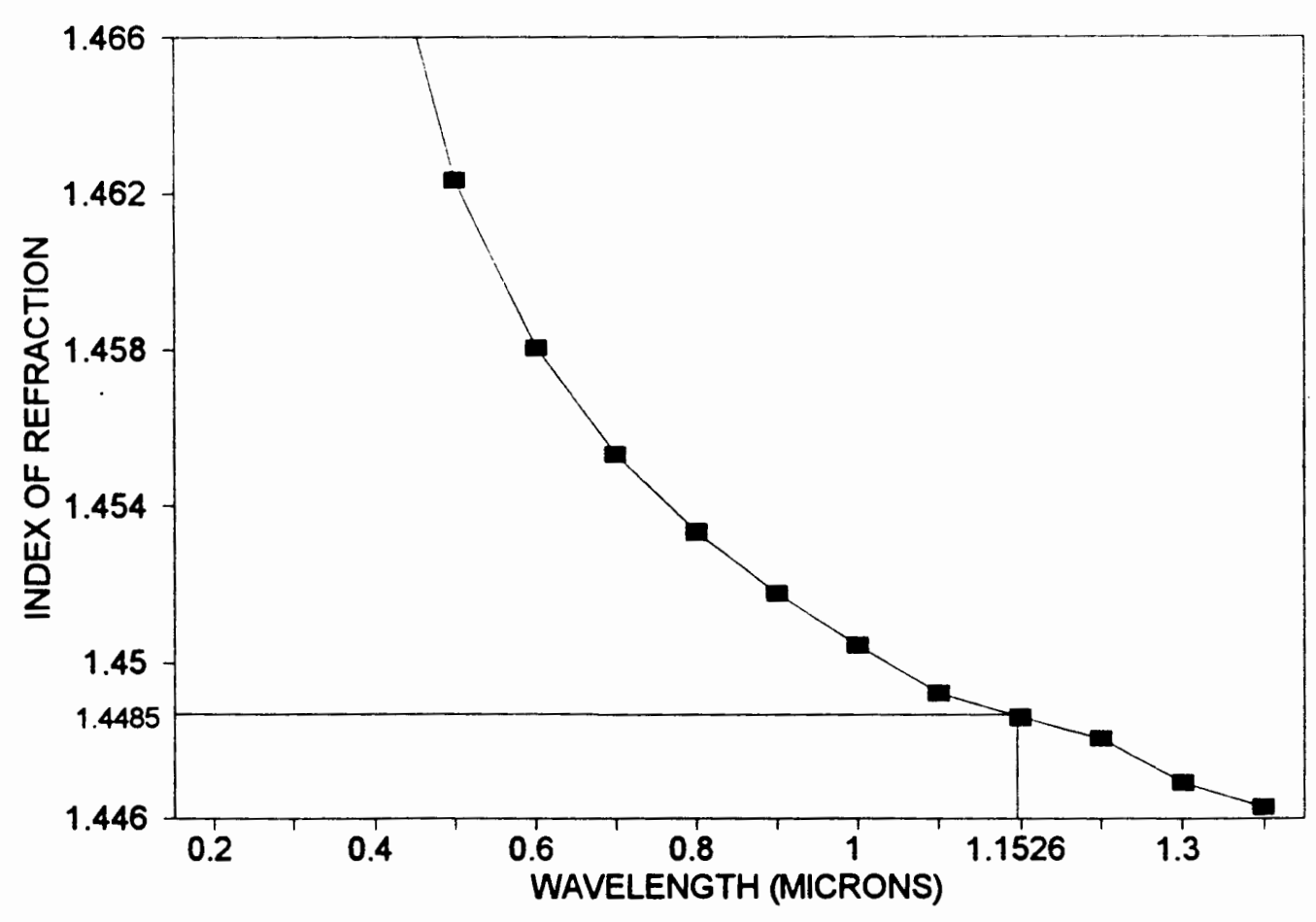

Figure 6. Index of refraction for fused-silica as a function of $\lambda(\mu \mathrm{m})$. 
Fused silica is a proper glass to use for it has a transmittance higher than $99.995 \%$ at $\lambda=1.152 \mu \mathrm{m}$, is more pure than fused quartz, and index matching fluids are more readily available for its values of $n$. The second (Ag) and third (Si) layers are the more involved layers, having both real and imaginary indices.

Unlike dielectric materials, metals (and certain other materials) have an imaginary as well as a real component in the index of refraction, making it

$$
n(T)=n(T)-i k(T) .
$$

complex: where we have indicated the temperature dependence explicitly. This complex index looks simple, but the process of obtaining $n(T)$ and $k(T)$ is an involved one.

To study the temperature effects on $n(T)$ and $k(T)$ for $A g$, we follow the work of Kikuo Ujihara. ${ }^{10}$ Using a Drude model and electron-phonon scattering theory, the optical constants $n(T)$ and $k(T)$ for $A g$ can be determined. We shall briefly modify Ujihara's work to make the computations self-consistent.

A simplistic view of the Drude model suggests a metal is an ocean of free-electrons where an impinging electromagnetic wave is damped by the collision frequency of the electrons by $\omega_{c}=1 / T$, where $T$ is the average time between collisions. The complex dielectric constant is given by : 


$$
\varepsilon\left(T_{\text {complex }}=1-\frac{\omega_{p}^{2}}{\omega\left(\omega+i \omega_{c}(T)\right)}\right.
$$

where the bulk plasma frequency $\omega_{p}$ is given by :

$$
\omega_{p}=\left(4 \pi N e^{2} / m *\right)^{\frac{1}{2}},
$$

with $m^{*}$ the effective electronic mass, $N$ the electron density, and $e$ the electron charge. Note that in [4.3] we have indicated explicitly that the temperature dependence of $\varepsilon$ comes from $\omega_{c}(T)$ and not from the plasma frequency, i.e. $\omega_{p} \neq \omega_{p}(T)$, since the change in plasma frequency due to temperature increase is insignificant. ${ }^{10}$

From the dielectric constant $\epsilon(T), n$ and $k$ can be derived. The first step in equating the optical constants is to multiply the second term in $\epsilon(\omega)$ by its conjugate $\left(\omega^{2}-i \omega \omega_{c}\right)$ :

$$
\varepsilon(\omega)=1-\frac{\omega_{p}^{2}}{\omega\left(\omega+i \omega_{\alpha}\right)} \cdot \frac{\left(\omega^{2}-i \omega \omega_{\alpha}\right)}{\left(\omega^{2}-i \omega \omega_{\alpha}\right)},
$$

to get the real and imaginary term

$$
\varepsilon(\omega)=1-\frac{\omega_{p}^{2}}{\omega^{2}+\omega_{c}^{2}}+i \frac{\omega_{p}^{2} \omega_{c}}{\omega\left(\omega^{2}+\omega_{c}^{2}\right)} .
$$


The next step is to equate the dielectric constant to $n$ and $k$

$$
\epsilon=(n+i k)^{2} \text {, }
$$

solving for two simultaneous equations

$$
\varepsilon=\varepsilon_{1}+i \varepsilon_{2}=\left(n^{2}-k^{2}\right)+i 2 n k=\left[1-\frac{\omega_{p}^{2}}{\omega^{2}+\omega_{c}^{2}}\right]+\left[i \frac{\omega_{p}^{2} \omega_{c}}{\omega\left(\omega^{2}+\omega_{c}^{2}\right)}\right] \text {, }
$$

with the real and imaginary dielectric constants defined as the following :

$$
\begin{aligned}
& \varepsilon_{1}=n^{2}-k^{2} \\
& \varepsilon_{2}=2 n k .
\end{aligned}
$$

Our work obtained the $n(T)$ and $k(T)$ in a different manner than Ujihara. In his approach one relies on the knowledge of $\boldsymbol{N}$ and $\boldsymbol{m}^{*}$, the plasma frequency $\boldsymbol{\omega}_{\mathrm{p}}$ is then calculated from [4.4]. Here we use the full implications from [4.8] [4.10] and obtain:

$$
\begin{aligned}
n^{2}-k^{2} & =1-\frac{\omega_{p}^{2}}{\omega^{2}+\omega_{c}(T)^{2}}, \\
2 n k & =\frac{\omega_{p}^{2}}{\left[\omega^{2}+\omega_{c}(T)^{2}\right]} \frac{\omega_{c}(T)}{\omega} .
\end{aligned}
$$


Then with the room temperature optical constants $n_{0}, k_{0}$; one can derive the room temperature collision frequency $\omega_{\text {co }}$ from [4.11] and [4.12]. We believe our method to be an improvement of Ujihara's method. Instead of using a calculated value of $\omega_{p}$, which is subject to much approximation, we use $n_{0}$ and $k_{0}$ in both [4.11] and [4.12], then solve [4.11] and [4.12] simultaneously to obtain $\omega_{p}$ and $\omega_{c o}$. Therefore our values for $\omega_{c o}$ and $\omega_{p}$ are self-consistent.

From this, it follows that $\omega_{\text {co }}$ can be determined since the room temperature values of the optical constants are known to be $n_{0}=.256$ and $k_{o}=7.83$ by interpolation ${ }^{11}$ from available data tabulated in the literature. By solving for $\omega_{c}$ using both [4.11] and [4.12], one arrives at an equation for $\omega_{\text {co }}$ and then for $\omega_{p}$,

$$
\begin{aligned}
& \omega_{c o}=\frac{2 n_{0} k_{0} \omega}{\left(1-n_{0}^{2}+k_{0}^{2}\right)}, \\
& \omega_{p}=\sqrt{\left(\omega^{2}+\omega_{c \partial}^{2}\right)\left(1-n_{0}^{2}+k_{0}^{2}\right)} .
\end{aligned}
$$

In order to determine the optical constants at elevated temperatures $\omega_{c}$ must be solved, thus we use a temperature dependent Debye model, ${ }^{10}$ 


$$
\omega_{c}=K^{\prime} \tau^{5} \int_{0}^{\frac{\theta_{0}}{T}} \frac{z^{4} d z}{e^{z}-1}
$$

With $\Theta_{0}$ the Debye temperature. In order to solve for $\omega_{c}$, the $K^{\prime}$ must first be determined. This is accomplished by arranging [4.15] so that $K^{\prime}$ is given by:

$$
K^{\prime}=\frac{\omega_{c o}}{\left[T_{0}^{5} \int_{0}^{\frac{\theta_{0}}{T_{0}}} \frac{z^{4} d z}{e^{z}-1}\right]},
$$

with $\omega_{c o}$ previously obtained as in [4.13]. The integral in [4.16] is done numerically by using an integral program available from the I.M.S.L. (international Mathematical and Statistical Library). The integration program uses a 21-point Gauss-Kronrod rule. ${ }^{12}$ Once $K^{\prime}$ is found, [4.15] can be computed. This, together with the assumption $\omega_{p} \neq \omega_{p}(T)$, will determine the complete temperature dependence for $\epsilon(T)$ through [4.3]. The temperaturedependent optical constants $n(T)$ and $k(T)$ can then be obtained using [4.9] and $[4.10]$ : 


$$
\begin{aligned}
& n=\frac{1}{\sqrt{2}}\left[\varepsilon_{1}+\sqrt{\left(\varepsilon_{1}{ }^{2}+\varepsilon_{2}{ }^{2}\right)}\right]^{\frac{1}{2}} . \\
& k=\frac{1}{\sqrt{2}}\left[\sqrt{\left(\varepsilon_{1}{ }^{2}+\varepsilon_{2}{ }^{2}\right)}-\varepsilon_{1}\right]^{\frac{1}{2}} .
\end{aligned}
$$

Now let us consider the Si layer. This Schottky barrier has a doped semiconductor layer (e.g. doped $\mathrm{Si}$ ), however in a paper by G.E. Jellison et $a^{13}$ , it was shown that for the optical constants doped Si and pure Si do not differ much for relatively low dopant concentrations. In their paper, consideration was given to both p-type and n-type semiconductors. This paper will consider pure $\mathrm{Si}$ from this point on to be analogous to doped $\mathrm{Si}$ as far as the values for $n(T)$ and $k(T)$ are concerned.

For pure $\mathrm{Si}, \mathrm{n}(\mathrm{T})$ and $\mathrm{k}(\mathrm{T})$ for a wavelength of $1.152 \mu \mathrm{m}$ has been studied by G.E. Jellison Jr. and D. H. Lowndes, ${ }^{14}$ and their results can be fit in terms of the absorption coefficient as a function of photon energy $(\boldsymbol{h v})$ and temperature as follows:

$$
\alpha(v, T)=\sum_{i=1}^{2} \sum_{i=1}^{2}(-1)^{\prime} \cdot \frac{\alpha\left[h v-E_{g}(T)+(-1)^{\prime} k \Theta_{j}\right]}{\left(e^{(-1)^{\prime} \frac{\theta_{1}}{T}}-1\right)},
$$

with $E_{0}$ the optical band gap, $\alpha_{i}$ the longitudinal and transverse acoustical phonon contributions, $\boldsymbol{h}$ the Planck constant and $k \Theta_{i}$ the phonon energies with $\Theta_{i}$ in degrees Kelvin. Knowing that : 


$$
\alpha=\frac{4 \pi k}{\lambda},
$$

$k(T)$ can be easily derived, this calculation is performed by the program in the appendix.

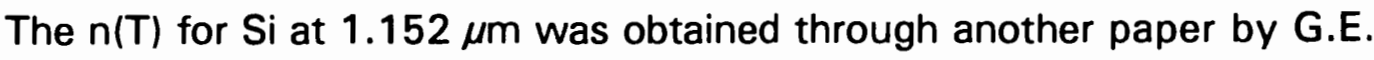
Jellison, Jr. and H. H. Burke ${ }^{15}$ with the formula :

$$
n(\lambda, T)=n_{0}(\lambda)+a_{n}(\lambda) T,
$$

for $\lambda=1.152 \mu \mathrm{m}, a_{n}(\lambda)$ is $2.15 \circ 10^{-4} / \mathrm{K}$. With these values the final $n(T)$ equation has the form :

$$
n(T)=3.45+2.15 \cdot 10^{-4} T
$$

Once these values for $n(T)$ and $k(T)$ are obtained where $n_{0}(\lambda)=3.45$ (interpolated at $1.152 \mu \mathrm{m}$ from reference 11 ), the range of temperature was chosen to be both favorable to Si and Ag. Since the m.p. of Si is $1420^{\circ} \mathrm{C}$ $(\cong 1693 \mathrm{~K})$ and for $\mathrm{Ag}$ is $960.5{ }^{\circ} \mathrm{C}(\cong 1233.5 \mathrm{~K})$ it was chosen to input temperatures ranging from room temperature to $800 \mathrm{~K}$ (900 $\mathrm{K}$ in some cases). Hence the $T$ values are well under the melting points for both materials.

Once the values of $n(T)$ and $k(T)$ are determined, polynomial curve fits are made for $k(T)$ that prove reasonable and the formulas are then incorporated into the Fresnel equations. The results and fit comparisons can 
$\operatorname{Ag} n(T)$

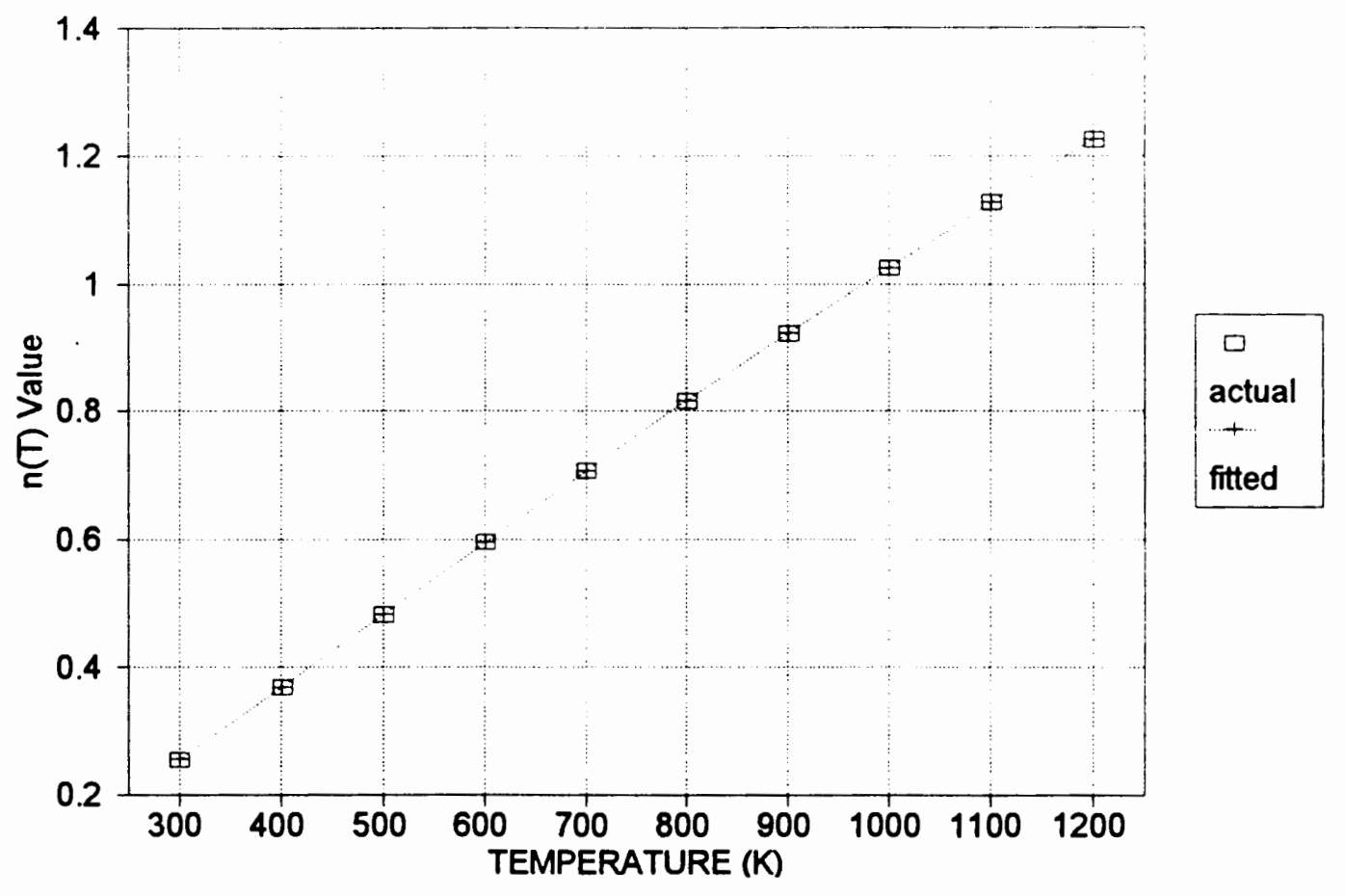

Figure 7. Real index of refraction for $\mathrm{Ag}$ as a function of temperature at $\lambda=1.152 \mu \mathrm{m}, \mathrm{n}(\mathrm{T})$. 


\section{Ag $k(T)$ INDEX OF REFRACTION}

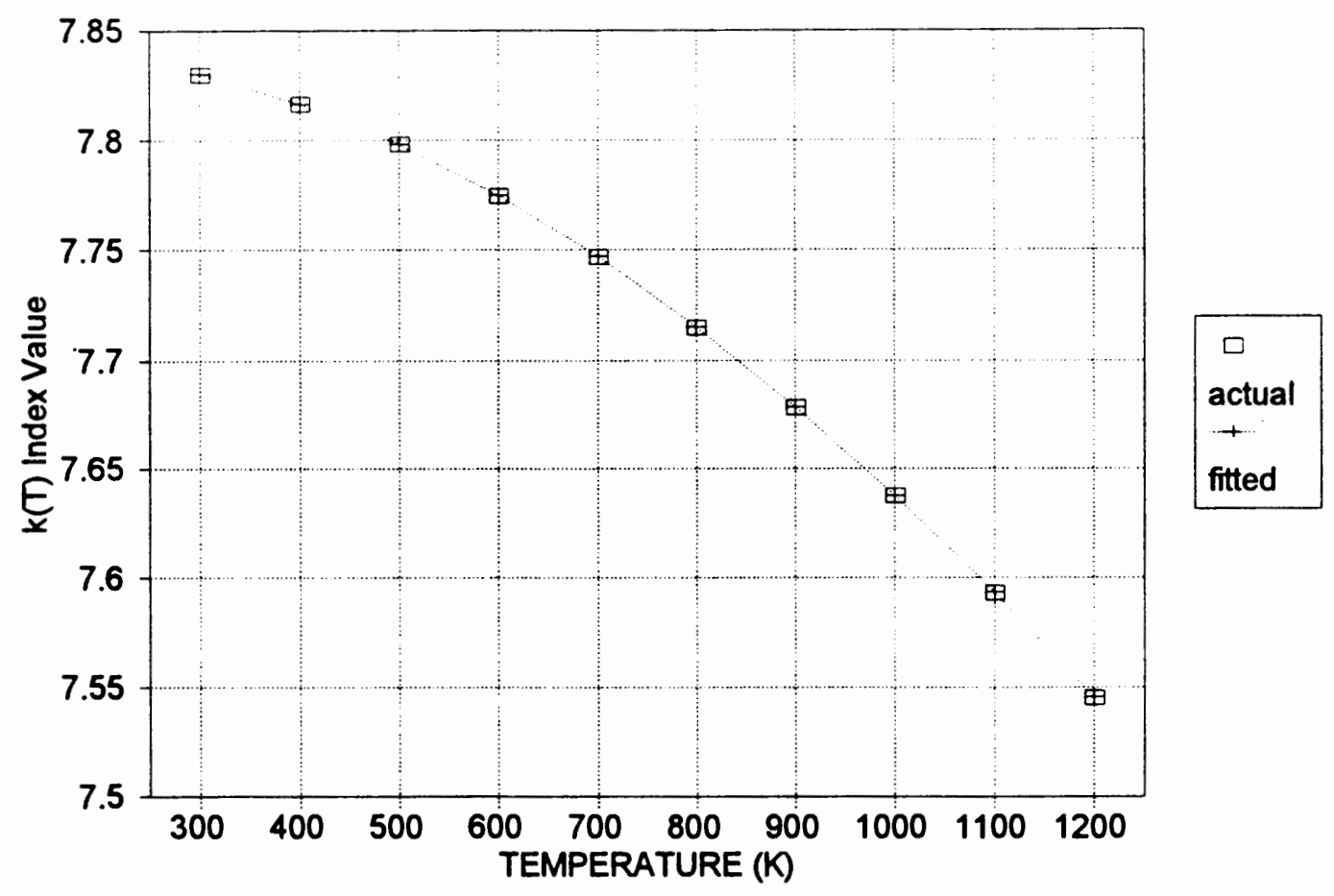

Figure 8. Imaginary index of refraction (extinction coefficient) for $\mathrm{Ag}$ as a function of temperature at $\lambda=1.152 \mu \mathrm{m}, \mathrm{k}(\mathrm{T})$. 


\section{$\operatorname{Sin}(T)$}

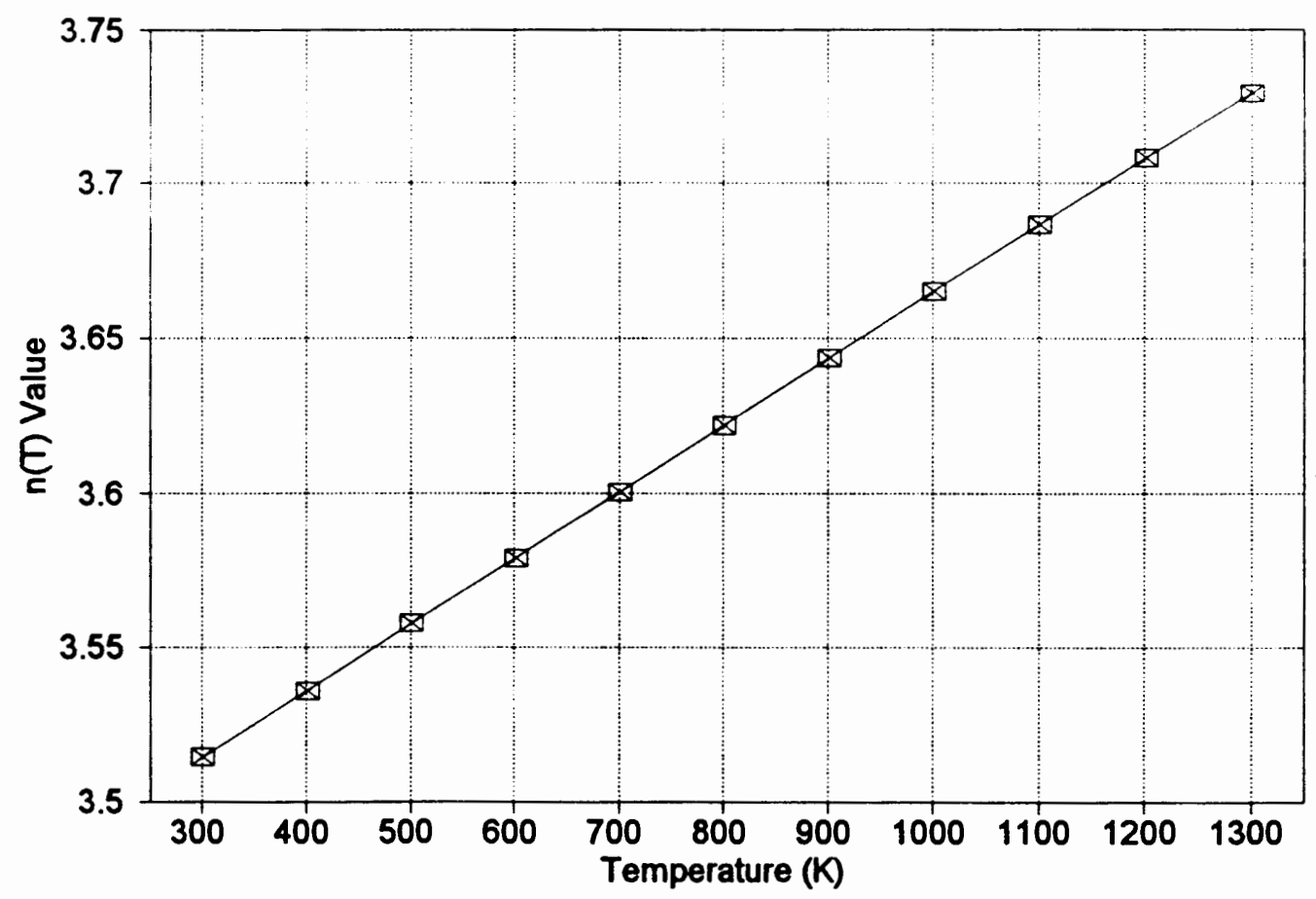

Figure 9. Real index of refraction for $\mathrm{Si}$ as a function of temperature at $\lambda=1.152 \mu \mathrm{m}, \mathrm{n}(\mathrm{T})$. 
Si k(T)

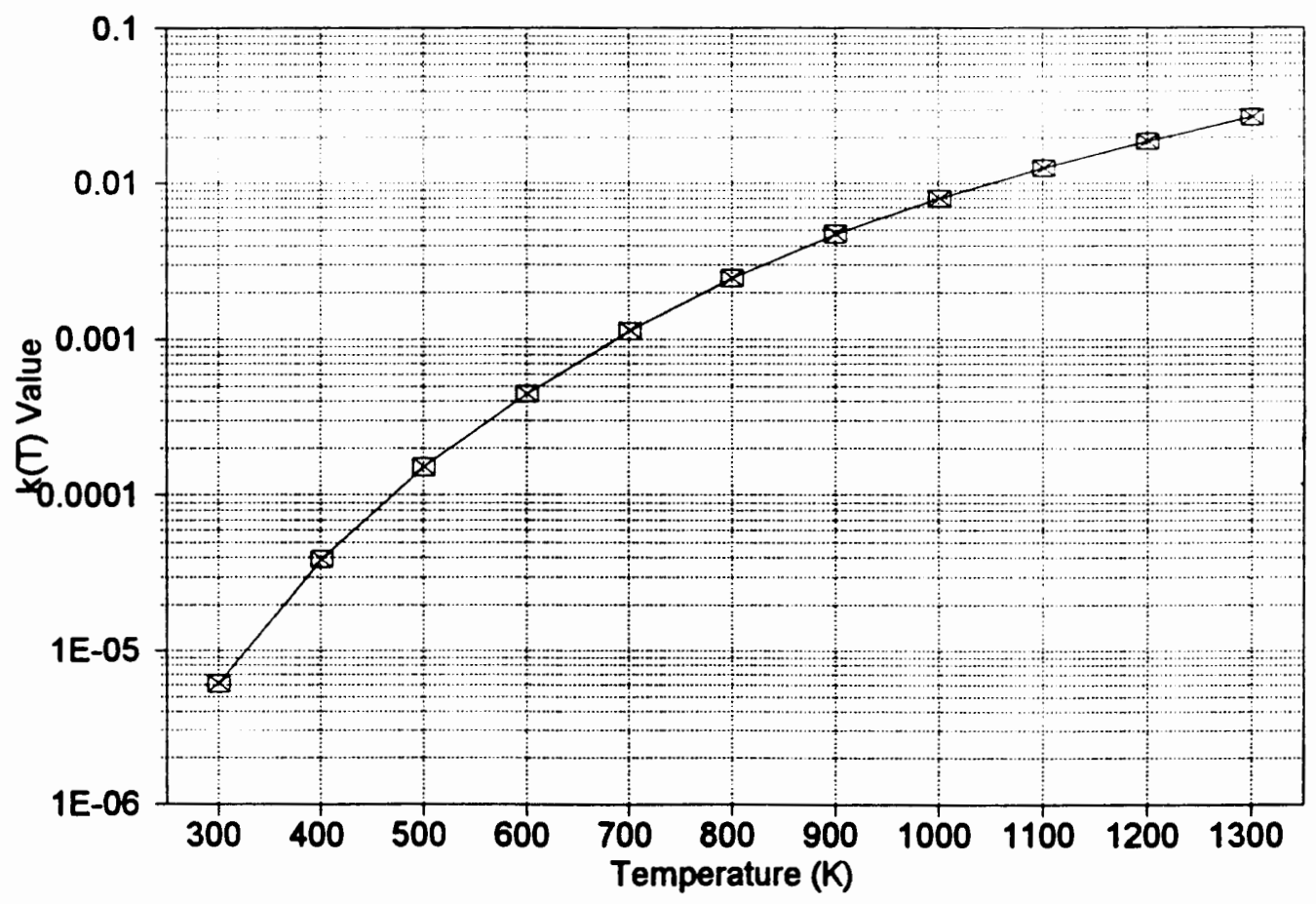

Figure 10. Extinction coefficient for $\mathrm{Si}$ as a function of temperature at $\lambda=1.152 \mu \mathrm{m}, k(T)$. Note the semilog scale used. 
be found in figures 7 through 10 .

Figure 7 shows the real index for $\mathrm{Ag}$ as a function of temperature. As the temperature increases - the real index value increases almost linearly. This result resembles Ujihara's work $^{13}$ for a wavelength of $1.06 \mu \mathrm{m}$. Figure 8 shows the extinction coefficient for $\mathrm{Ag}$ as a function of increasing temperature. This result is also predicted by Ujihara's work for $1.06 \mu \mathrm{m}$.

Figure 9 shows the real index for $\mathrm{Si}$ as a function of temperature. This result is expected from the work of G.E. Jellison, Jr. and H. H. Burke ${ }^{15}$ : as temperature increases, the real index increases linearly. In figure 10, the extinction coefficient for $\mathrm{Si}$ is shown increasing as a function of increasing temperature. This result is also expected according to G.E. Jellison, Jr. and D.H. Lowndes. It is important to mention that the polynomials used for fitting the optical constants for $\mathrm{Ag}$ and $\mathrm{Si}$ are very close fits, such that the actual data and fitted data cannot be visually distinguished from one another on the graphs.

Since the optical constants of all materials in our setup are defined, they can now be incorporated into the Fresnel equations to determine the reflectivity $\boldsymbol{R}$ for our chosen system. The Fresnel equations used in the programs are for a four layer system - fused silica (layer 1), Ag (layer 2), Si (layer 3), and air (layer 4) (see Fig. 4). It is crucial that the Fresnel equation for the case of an incident wave that has an E-field in the plane of incidence (p-polarization). The reflectivity is given by $:^{16}$ 


$$
R=\left|r_{14}\right|^{2}=\left|\frac{r_{12}+r_{24} e^{-2 k_{22} d_{2}}}{1+r_{12} r_{24} e^{-2 k_{22} d_{2}}}\right|^{2} \text {, }
$$

where $r_{24}$ and $r_{i, i+1}$ are defined as :

$$
\begin{aligned}
& r_{24}=\frac{r_{23}+r_{34} e^{-2 k_{32} d_{3}}}{1+r_{23} r_{34} e^{-2 k_{32} d_{3}}}, \\
& r_{1,1+1}=\frac{\sqrt{\varepsilon_{1+1}} \cos \theta_{1}-\sqrt{\varepsilon_{1}} \cos \theta_{1+1}}{\sqrt{\varepsilon_{1+1}} \cos \theta_{1}+\sqrt{\varepsilon_{1}} \cos \theta_{1+1}} .
\end{aligned}
$$

The wave vectors in [4.23] and [4.24] are given by :

$$
k_{k}=-\frac{i \omega}{c} \sqrt{\varepsilon_{1}-\varepsilon_{1} \sin ^{2} \theta_{1}} .
$$

The square root term can be expressed more simply since :

$$
\cos \theta_{1}=\sqrt{1-\frac{\varepsilon_{1}}{\varepsilon_{1}} \sin ^{2} \theta_{1}},
$$

hence it follows that :

$$
k_{k}=-i \frac{\sqrt{\varepsilon_{1} \omega}}{c} \cos \theta_{1} .
$$

Equations [4.23] through [4.28] are incorporated into the Fortran modeling program in the appendix. 


\section{CHAPTER V}

\section{RESULTS}

The results of the fortran program for modeling the SPR effect at elevated temperatures are shown through fig. 11 to fig. 27. Many different phenomena such as horizontal and vertical shifting and broadening can be seen in the graphs. It is important to mention that as the temperature increases, the layers are expanding, this has been taken into account in the programs by calculating the corrected thickness' as functions of temperature using Poisson ratios for both $\mathrm{Ag}$ and $\mathrm{Si}^{2}$ The equation for thermal expansion is the following:

$$
\alpha^{\prime}=\alpha \frac{(1+\mu)}{(1-\mu)}
$$

for Ag the Poisson factor, $\mu$ is 0.3 and $\alpha=1.87 \times 10^{-5},{ }^{2}$ for Si $\mu=.25$ and $\alpha=$ $2.33 \times 10^{-6} .{ }^{17}$ These values are then put into a correction equation for thickness:

$$
d^{\prime}=d\left(1+\alpha^{\prime}(T-300 K)\right)
$$

where $\boldsymbol{d}$ is the room temperature thickness, $\mathbf{T}$ is temperature (in Kelvin) and $\boldsymbol{\alpha}^{\prime}$ is already calculated. In our results these factors overall were not crucial, but definitely worth reporting, the maximum expansion of thickness in $\mathrm{Ag}$ at 900 
$\mathrm{K}$ (or $600{ }^{\circ} \mathrm{C}$ ) was $.83 \mathrm{~nm}$ at a $40 \mathrm{~nm}$ Ag thickness. The maximum expansion for $\mathrm{Si}$ is $.53 \mathrm{~nm}$ at $900 \mathrm{~K}$ at $230 \mathrm{~nm}$ Si thickness (upper end of first waveguide mode thickness). In general the effects due to this expansion is not visible in the graphs, but does exist.

Another important experimental consideration is that of an oxide growth layer on the $\mathrm{Ag}$ and $\mathrm{Si}$ as a result of being subjected to high temperatures in normal lab environment. The oxide growth of $\mathrm{Si}$ is $\cong 17 \AA$ at less than or equal to $673 \mathrm{~K}$ and increases to $\cong 27 \AA$ up to $973 \mathrm{~K}^{18}$ For $\mathrm{Ag}$ the oxide growth is not considered since the metal layer in our arrangement is between the prism and the Si. Since the oxide growth factor is not significant, they are not factored into the modeling programs.

The first resulting graph, figure 11 , is justification for using a standard $40 \mathrm{~nm}$ thickness for the Ag layer. From the graph it can be seen that at $40 \mathrm{~nm}$ (at room temperature) the SPR dip for the reflectance is sharpest, trying other values even $1 \mathrm{~nm}$ or $2 \mathrm{~nm}$ away from $40 \mathrm{~nm}$ in either direction result in a broader dip curve. This value turns out to be very close to the value chosen also for $\mathrm{Au}^{6}{ }^{6}$ Once the optimum value for the $\mathrm{Ag}$ thickness is determined, it is kept constant (except being subjected to thermal expansion) for all $\mathrm{Si}$ thickness'.

Figure 12 shows the SPR curves for an increasing Si thickness up to 50 $\mathrm{nm}$ (10 nm increments) at room temperature. It can be seen how the resonance dip position is shifted to the right as the Si layer increases and it 


\section{SPR CURVES FOR 0-50 nm THICK Ag}

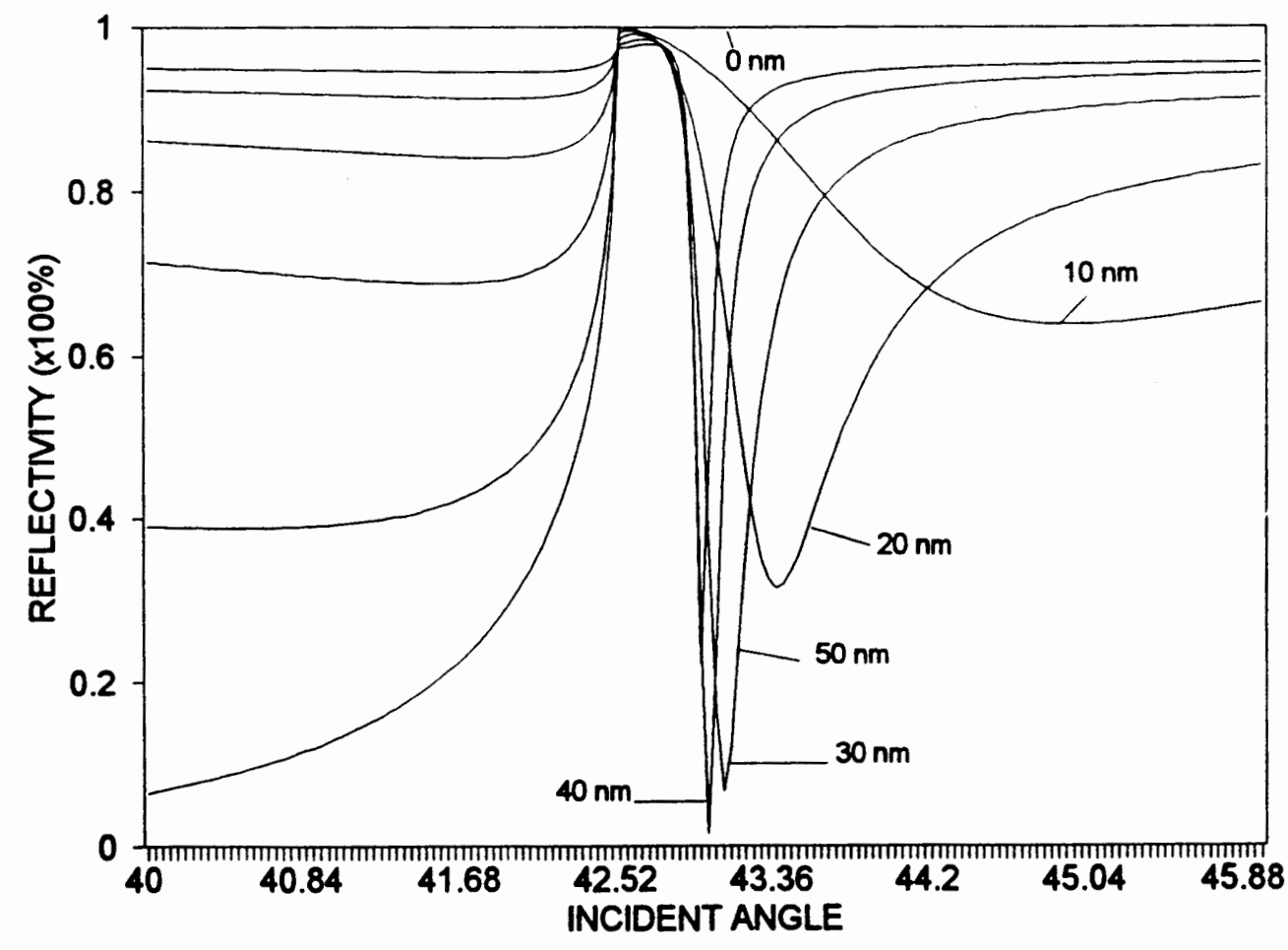

Figure 11. Optimum Ag SPR dip occurrence at $40 \mathrm{~nm}$ thickness. 


\section{SPR CURVES for 0 to $50 \mathrm{~nm} \mathrm{Si}$}

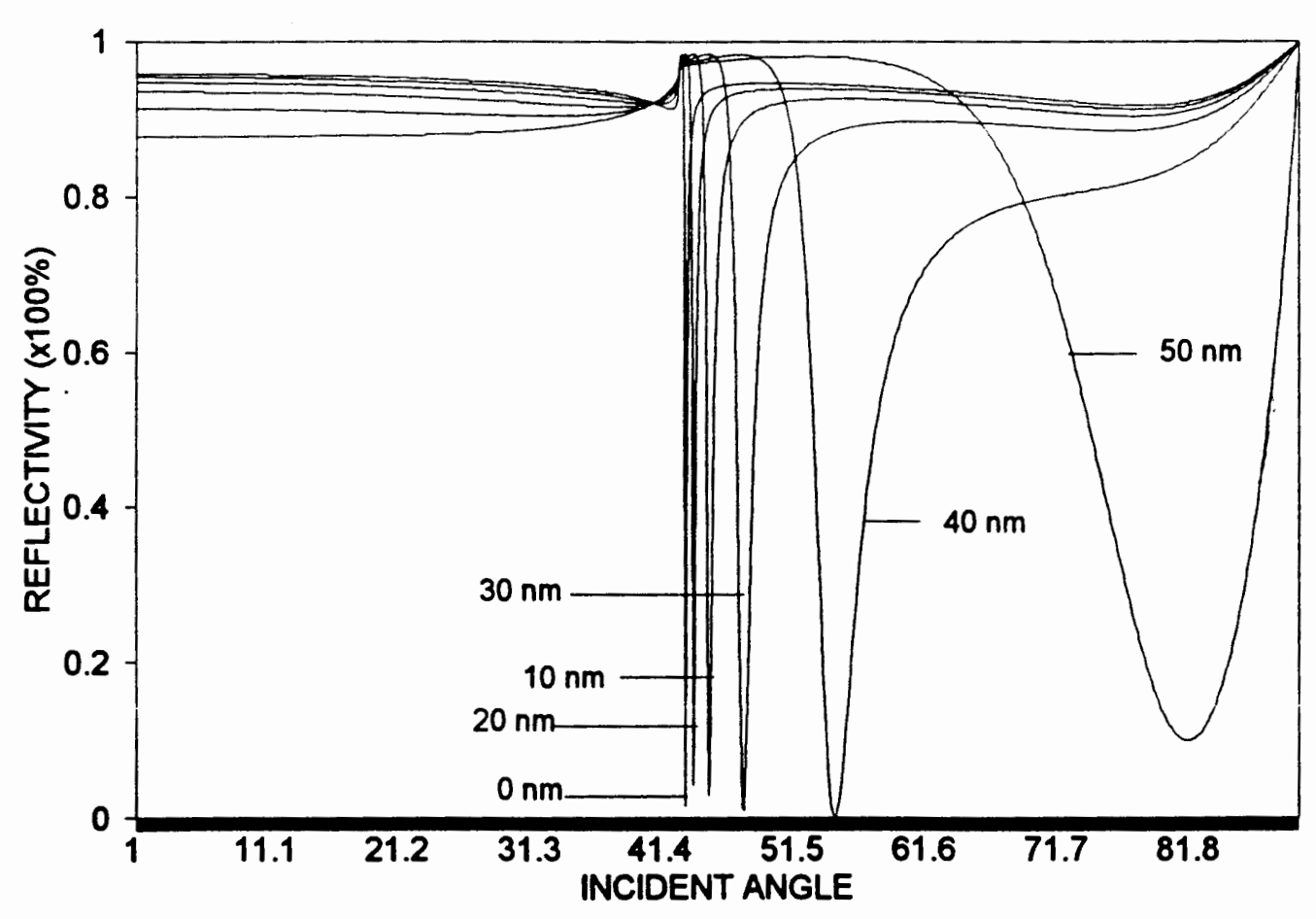

Figure 12. SPR curves for 0 to $50 \mathrm{~nm}$ Si on a $40 \mathrm{~nm}$ layer of $\mathrm{Ag}$. 
broadens as well as decreases in amplitude. It can also be shown that $\mathrm{Si}$ thickness' greater than approximately $53 \mathrm{~nm}$ the SPR dip disappears only reappearing as a similar curve as a result of a guided wave surface polaritons (GWSP's) at approximately $129 \mathrm{~nm}$. A similar result has been seen by $\mathrm{S}$. Herminghaus and P. Liederer, ${ }^{19}$ when using a Kretschmann configuration with a metal layer of $\mathrm{Ag}$ and a dielectric of Polymethylmethacrylate (PMMA). This result can be seen in figure 13 . The GWSP curve is interesting but this paper will deal only with the SPR portion (up to $53 \mathrm{~nm}$ of Si). Figure 13 shows the an increase in SPR angle (shifting to the right) as the thickness of Si increases. By the time the Si thickness is a few nanometers away from $53 \mathrm{~nm}$, the SPR dip has become so broad that it really can't be considered a significant dip and this occurs at about 87 degrees in the minimas' position. Based on this, the left-shifting data points near $53 \mathrm{~nm}$ are not significant.

In figure 14, just the SPR mode dip position is shown as a function of $\mathrm{Si}$ thickness at selected elevated temperatures. Nothing is noticeable in dip position until approximately $30 \mathrm{~nm}$ of $\mathrm{Si}$ is reached, at that point shifting occurs. The curves appear to shift left as temperature increases, resulting in right shifting in dip position faster than at room temperature. As temperature increases it can also be seen that the dip angles reach a lower maximum right shift. These results are not outstanding but a general trend can be seen. Figure 15 is the same as figure 14 with the additional effect the heated fused silica. The effect at elevated temperatures is not noticeable in terms of SPR 


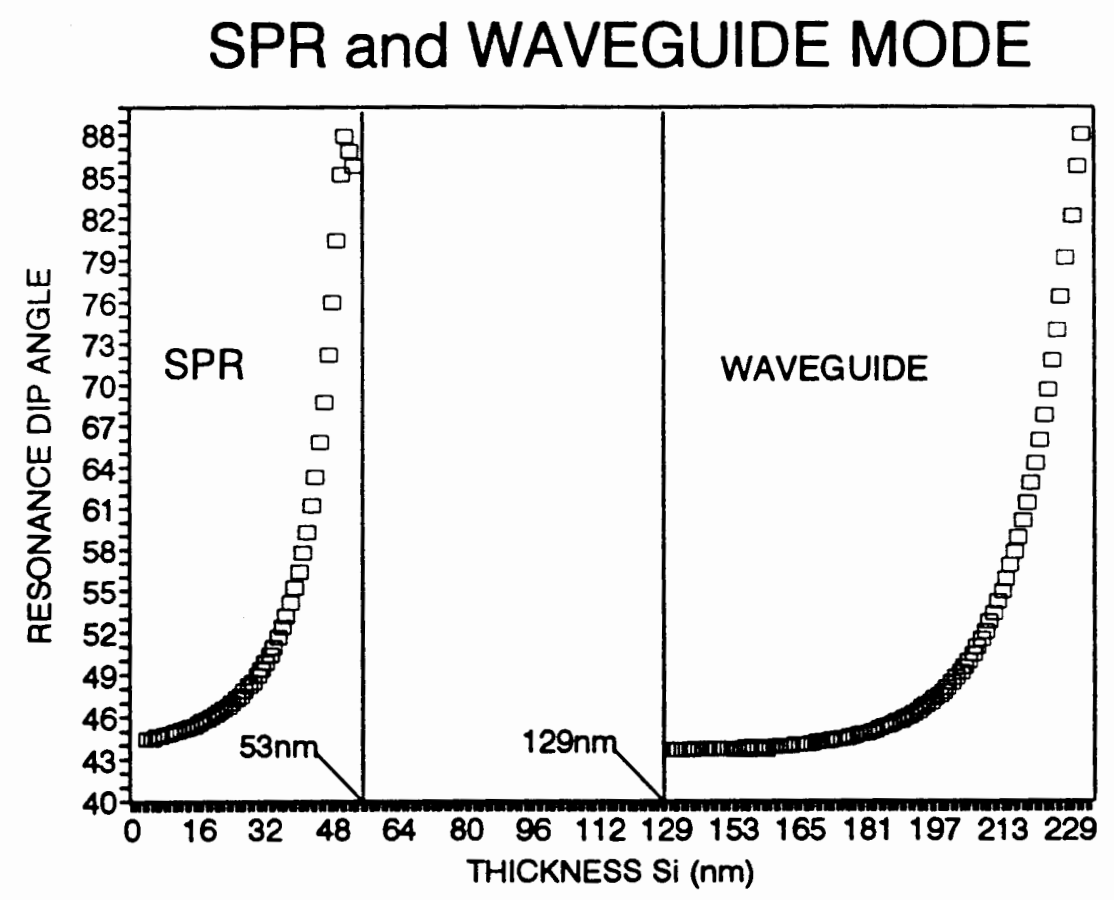

Figure 13. SPR and Waveguide mode resonant dip angles versus $\mathrm{Si}$ thickness. 
SPR Mode

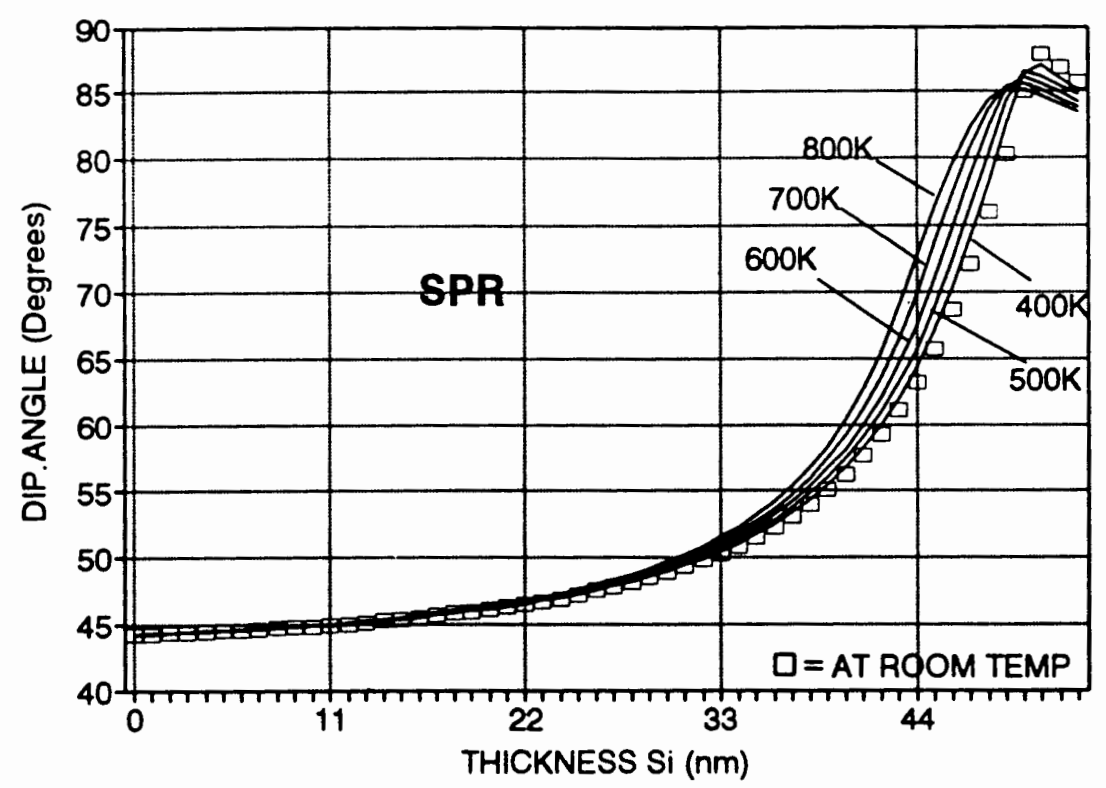

Figure 14. SPR dip angle at elevated temperatures on a 0 to $53 \mathrm{~nm} \mathrm{Si}$ thickness. 


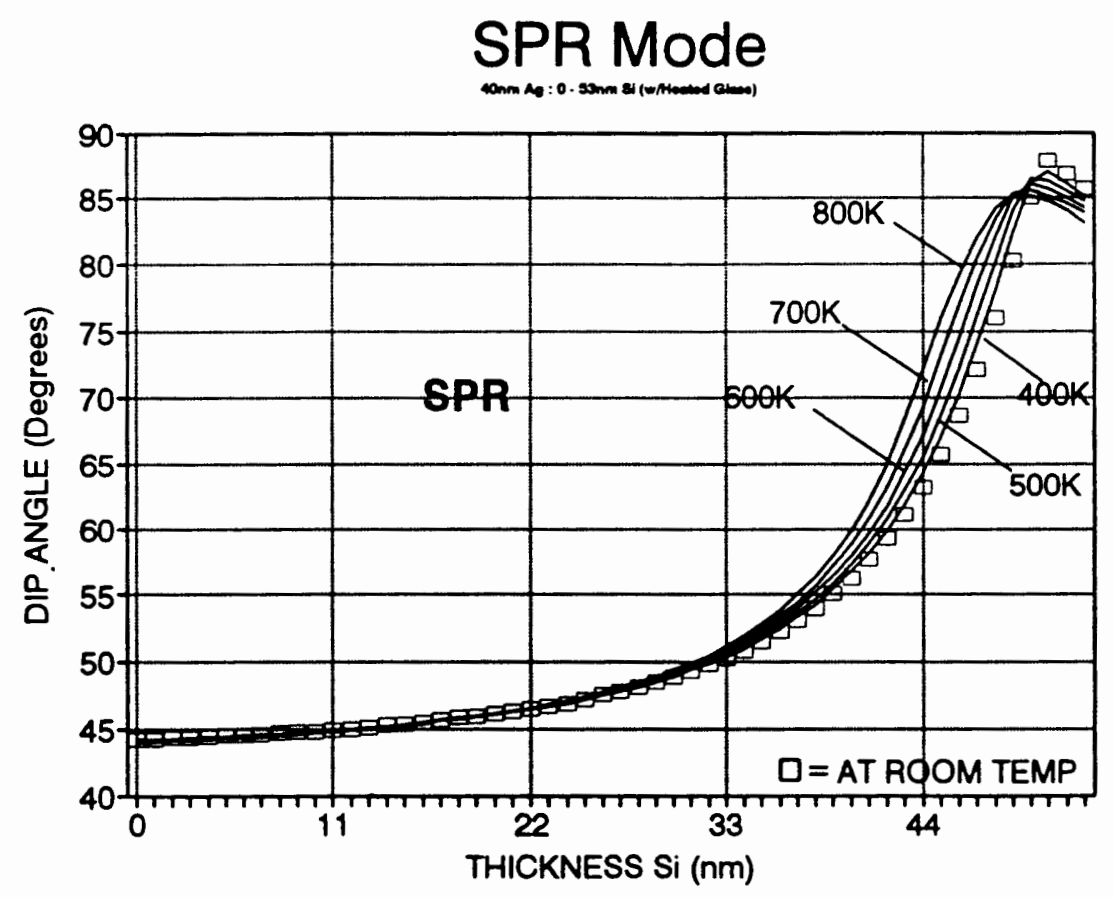

Figure 15. SPR dip angle at elevated temperatures on a 0 to $53 \mathrm{~nm} \mathrm{Si}$ thickness $w /$ heated glass effect. 
dip position.

Figure 16 is a graph of SPR reflectance-vs-incident angle at elevated temperatures for a $40 \mathrm{~nm} \mathrm{Ag} \mathrm{layer} \mathrm{only.} \mathrm{It} \mathrm{can} \mathrm{be} \mathrm{seen} \mathrm{that} \mathrm{as} \mathrm{temperature}$ increases the dip becomes shallower and broadens. A very small shift to the right can also be seen in the dip position as temperature increases. This graph explains the results for reflectance change of figure 17 . In figure 17 , as the temperature increases, the SPR dip angle appears unshifted and the right side decreases. The very small right-shift coupled with slight broadening to the left of the SPR dip angle position of figure 16, cancel each other to create the unshifted peak resul for $\Delta R$ at the SPR angle. Figure 18 indicates the $\Delta R$ at the SPR angle $\left(44.18^{\circ}\right)$ only as a function of elevated temperatures. The change in reflectance is almost linear with respect to the temperature. Figure 19 is the same as figure 17 but with the additional heated glass effect. This figure indicates a very slight left-shift in the SPR angle; however, only the critical angle appears to be significantly affected. The rest of the figures involve an additional layer of Si of $30 \mathrm{~nm}$ and $40 \mathrm{~nm}$ thickness', these values were chosen because they are well within the $\mathrm{Ag}-\mathrm{Si}$ SPR thickness range $(\leqslant 10 \mathrm{~nm}$ to $53 \mathrm{~nm})$.

Figure 20 is a graph of the SPR reflectance-vs-incident angle at elevated temperatures for a $40 \mathrm{~nm}$ Ag layer and $30 \mathrm{~nm}$ Si layer. This graph shows both a significant right-shift, broadening and shallower dip as temperature increases. This graph leads to the results of $\Delta R$ in figure 21 . This result is similar to the 
Ag Only: at elevated Temp.

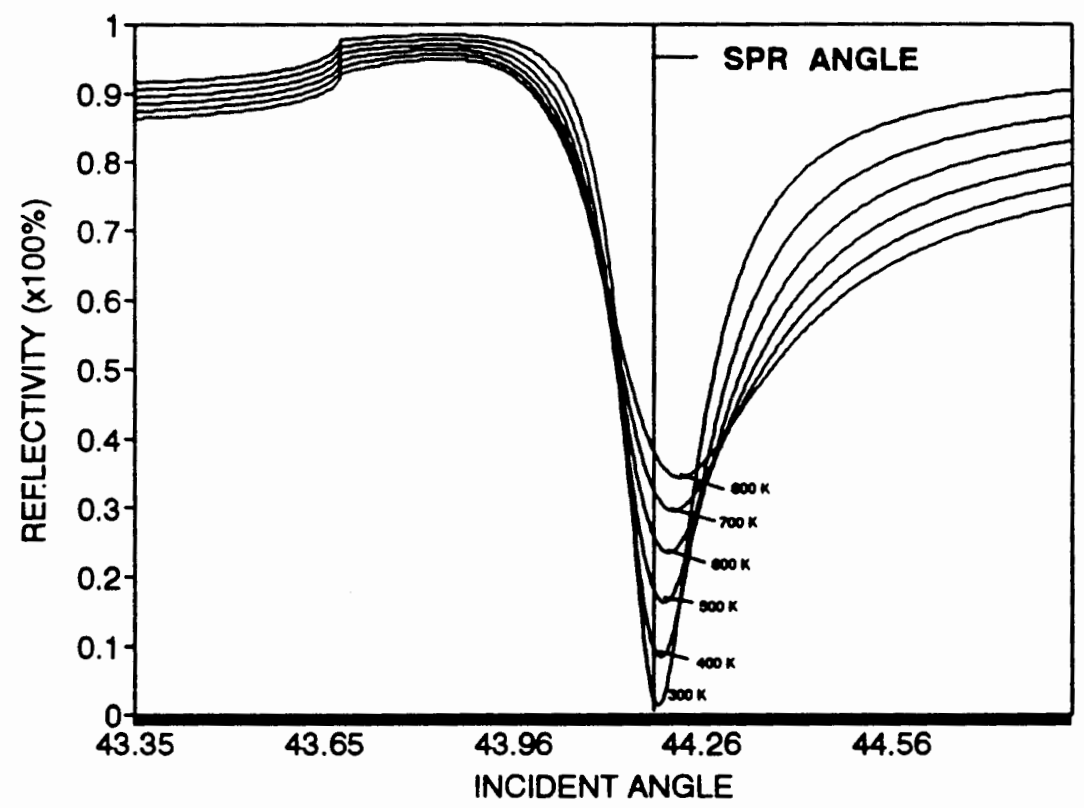

Figure 16. SPR reflectivity at elevated temperatures - $\mathrm{Ag}(40 \mathrm{~nm})$ only. 


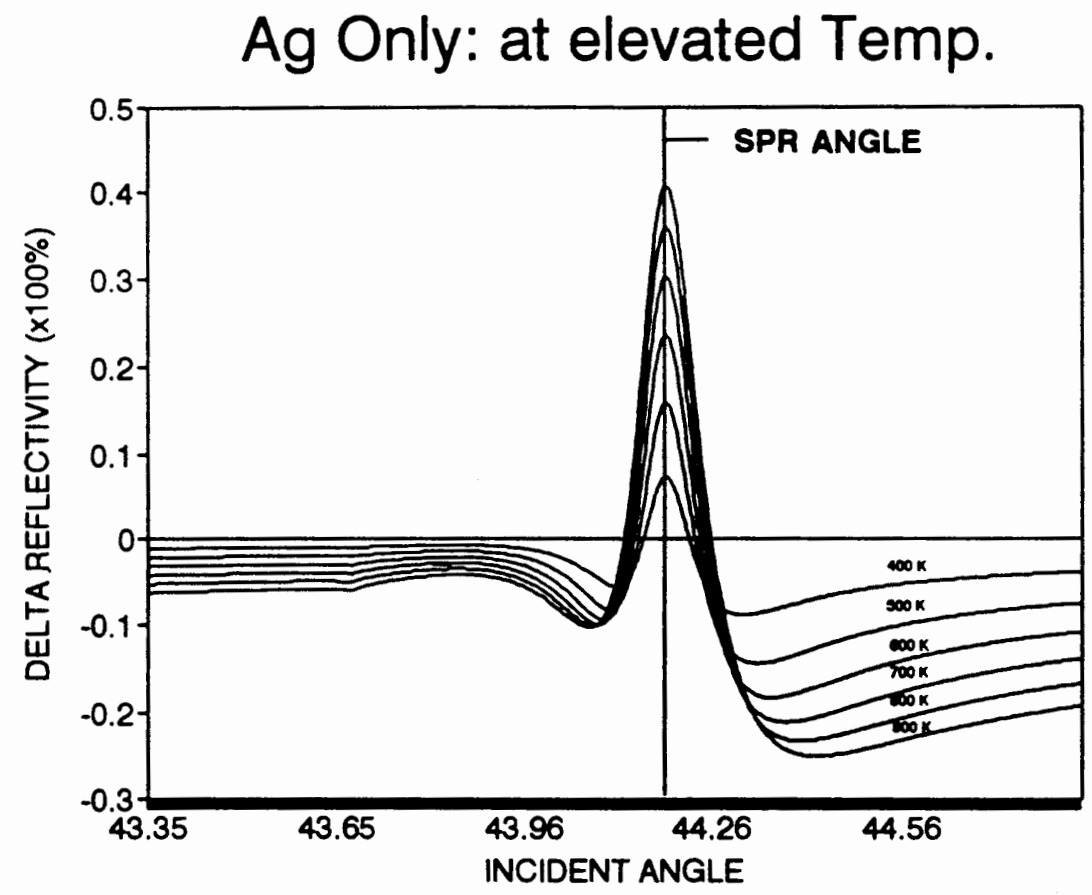

Figure 17. Change of SPR reflectivity $(\Delta R)$ at elevated temperatures - Ag 140 $\mathrm{nm}$ ) only. 


\section{REFL. CHANGE AT SPECIFIED ANGLE}

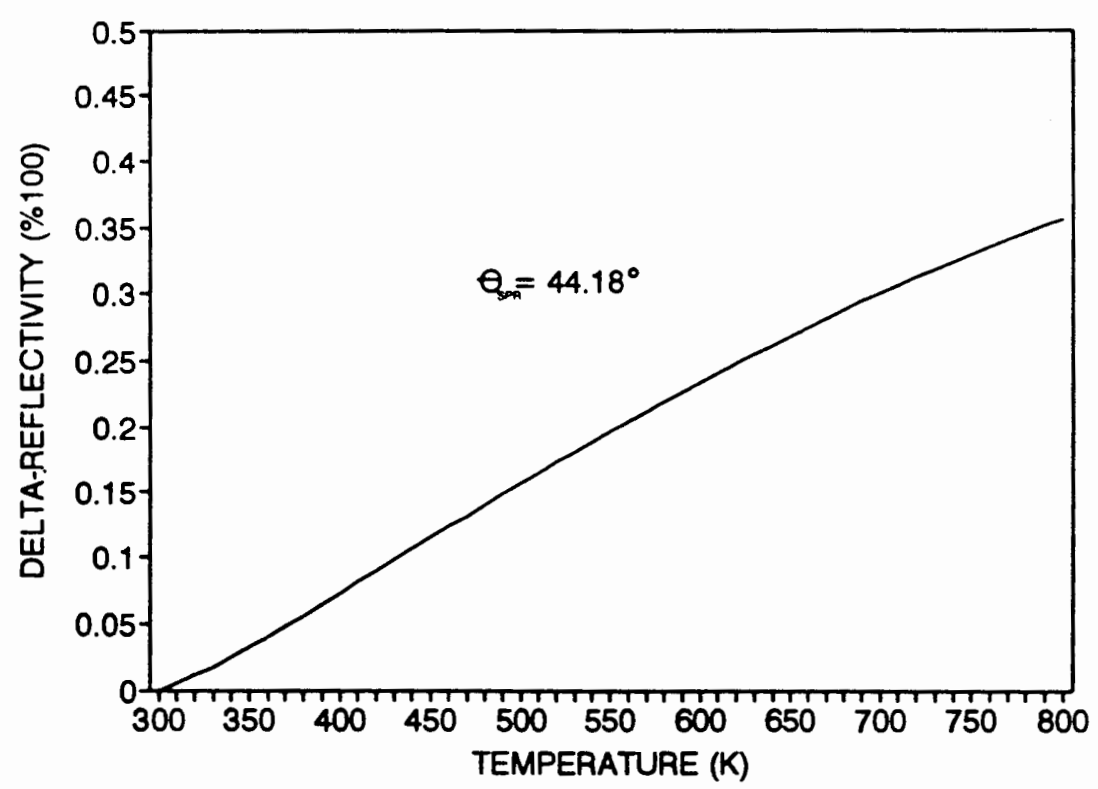

Figure 18. SPR $\triangle R$ at SPR angle $\left(44.18^{\circ}\right)$ at elevated temperatures - $\mathrm{Ag}$ (40 $\mathrm{nm}$ ) only. 


\section{Ag Only: at elevated Temp.}

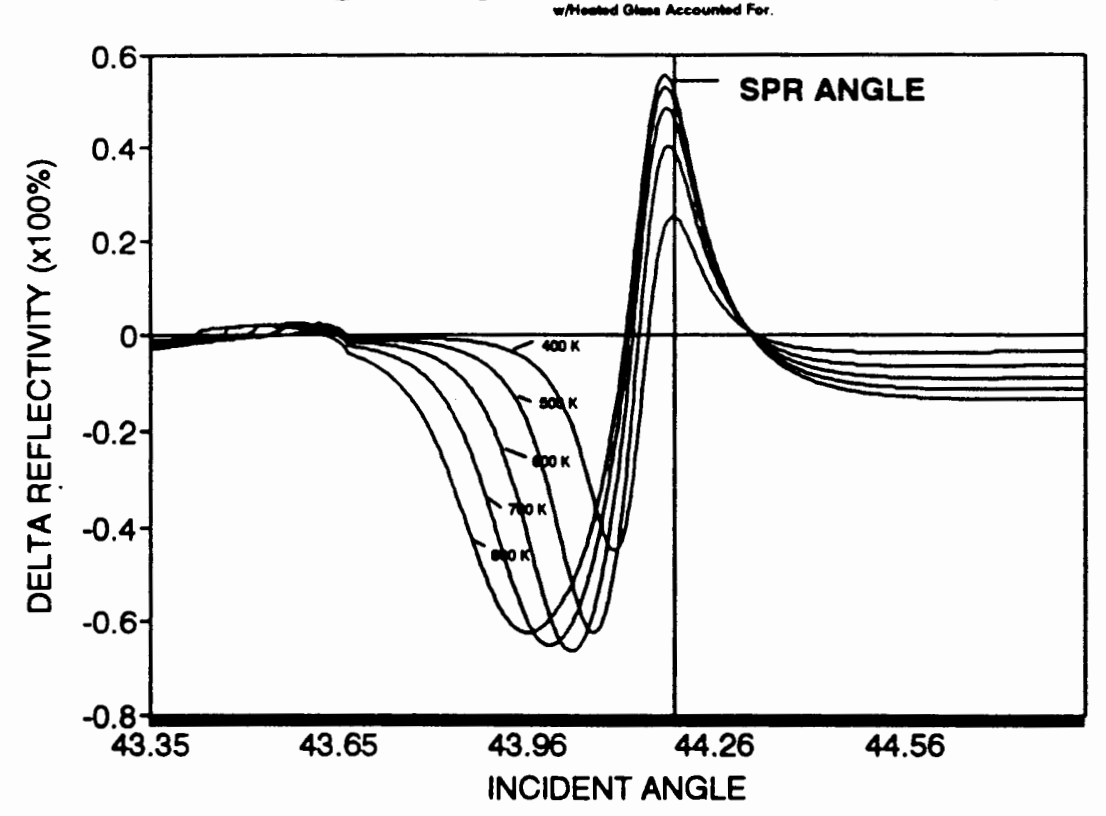

Figure 19. SPR $\triangle R$ at elevated temperatures - Ag $(40 \mathrm{~nm})$ only, w/ heated glass effect. 
pure Ag case. Figure 22 is a graph showing an almost linear dependence on the $\Delta R$ at the SPR angle $\left(48.85^{\circ}\right)$ as a function of temperature. It is important to note that the slope is steeper than that in figure 18 , indicating that the $\Delta R$ is greater at the SPR angle. Figure 23 is the same graph as figure 21, but with a heated glass effect. The SPR position seems unaffected in this graph, but there is a slight decrease in amplitude at the SPR position as temperature increases.

The next graph, figure 24 is a graph the SPR reflectance-vs-incident angle at elevated temperatures for a $40 \mathrm{~nm} \mathrm{Ag} \mathrm{layer} \mathrm{and} \mathrm{a} 40 \mathrm{~nm}$ Si layer. In this case the shift and broadening are most pronounced. The $\Delta R$ graph of figure 25 can be easily misread if not for the SPR line to indicate where the actual angle of SPR is occurring. The shift in the SPR dip angle in figure 25 is not noticeable, only a definite broadening and shallower dip can be noticed. This effect is more pronounced than for the pure $\mathrm{Ag}$ and thinner Si layer cases at elevated temperatures. Similar to both figures 18 and 22, figure 26 indicates an almost linear relationship as a function of temperature at the SPR angle $\left(56.20^{\circ}\right)$. In figure 26 , the line is even steeper than the pure $\mathrm{Ag}$ and $30 \mathrm{~nm} \mathrm{Si}$ case, which may indicate that the $\Delta R$ is greater as the Si layer increases. Figure 27 has the heated glass effect incorporated. Similar to the pure $\mathrm{Ag}$ and $30 \mathrm{~nm}$ Si case the heated glass effect slightly decreases the amplitude of the SPR reflectance but doesn't seem to affect the SPR angle significantly. 


\section{Si:30nm \& Ag:40nm / ELEV. TEMP}

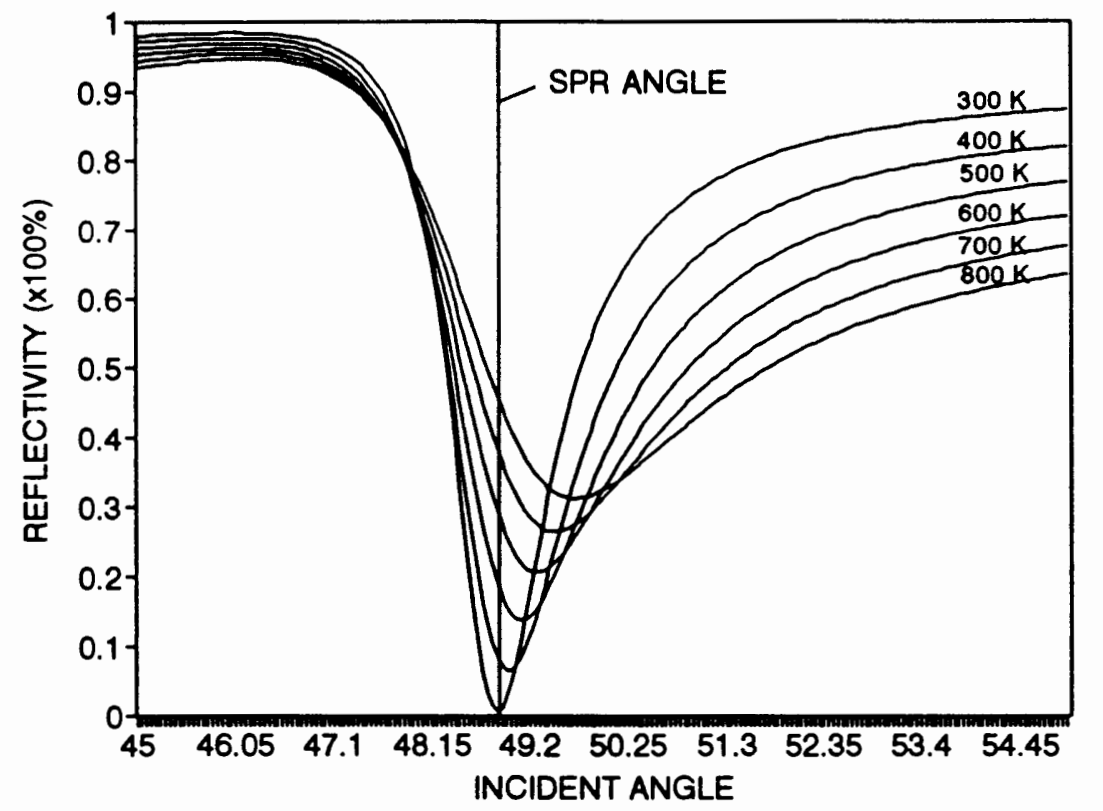

Figure 20. SPR reflectivity at elevated temperatures - Ag $(40 \mathrm{~nm}) \&$ Si (30 $\mathrm{nm})$. 


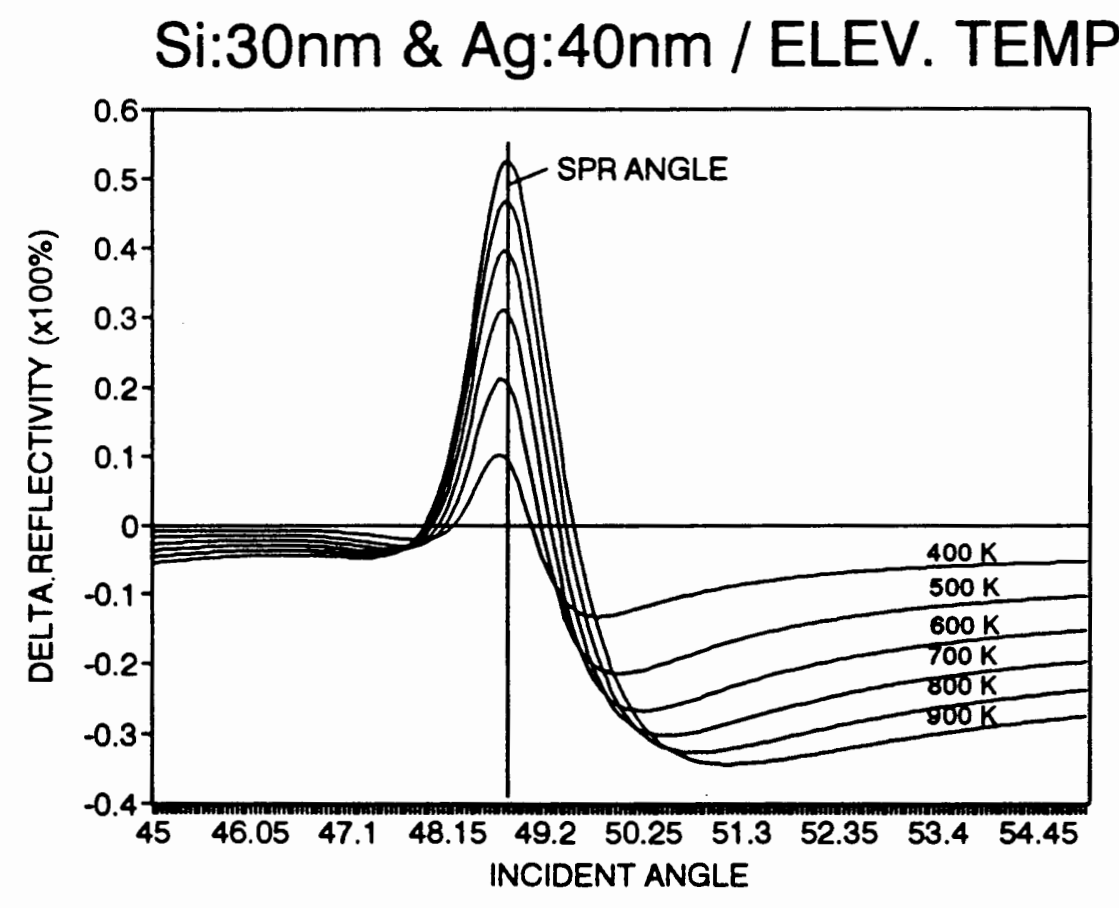

Figure 21. SPR $\triangle R$ at elevated temperatures - $A g(40 \mathrm{~nm}) \& S i(30 \mathrm{~nm})$. 


\section{REFL. CHANGE AT SPECIFIED ANGLE}

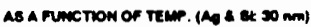

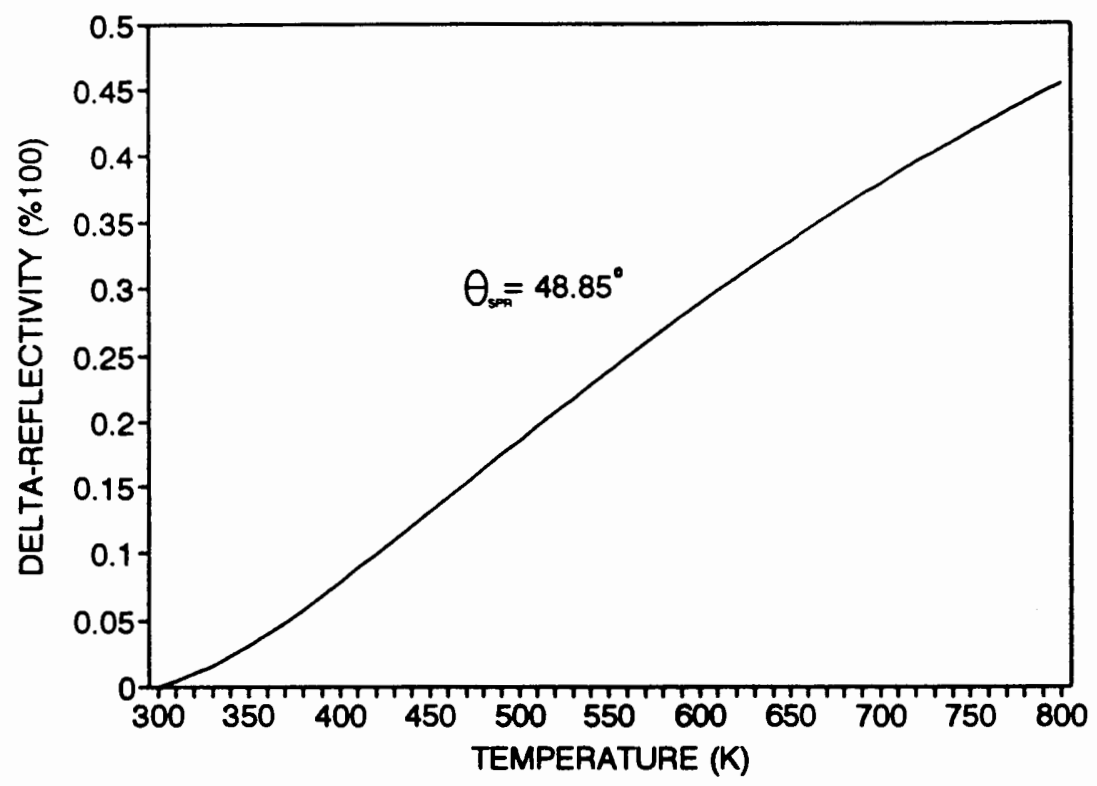

Figure 22. SPR $\triangle R$ at $\mathrm{SPR}$ angle $\left(48.85^{\circ}\right)$ at elevated temperatures - Ag $(40$ $\mathrm{nm})$ \& Si $(30 \mathrm{~nm})$. 


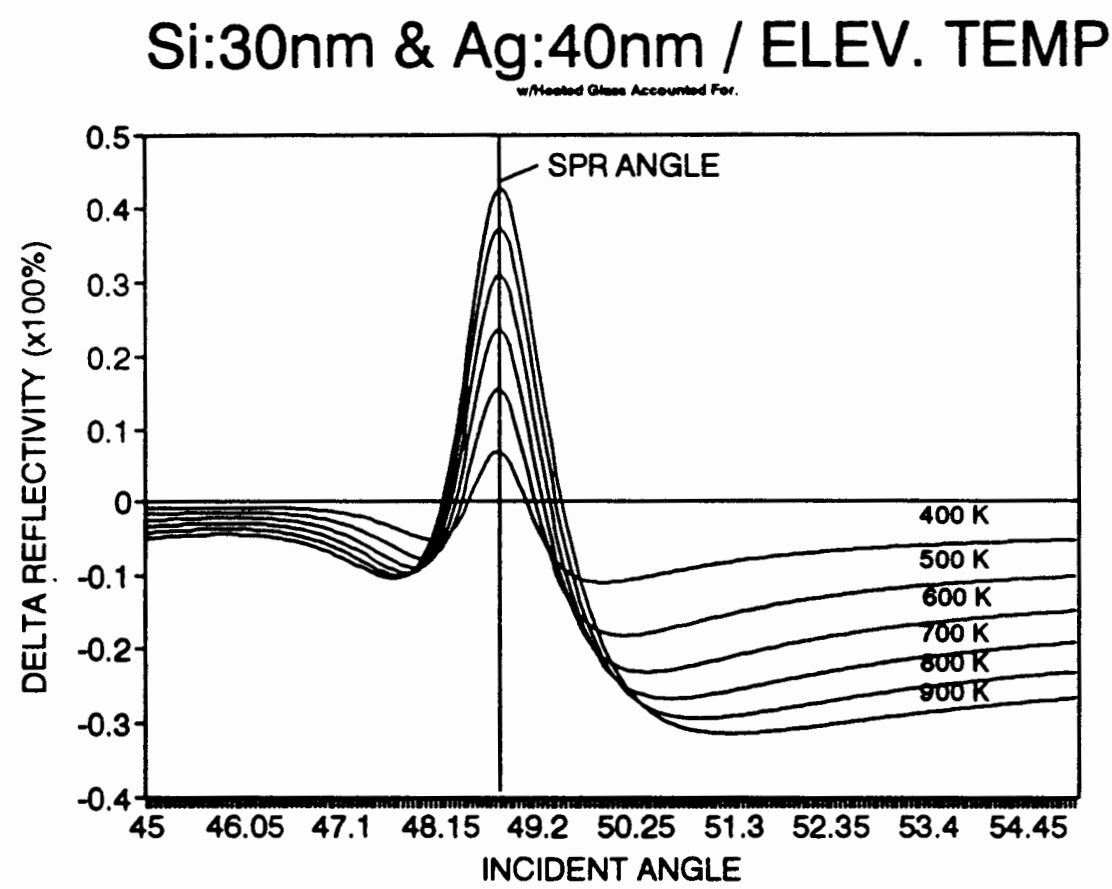

Figure 23. SPR $\Delta R$ at elevated temperatures - $A g(40 \mathrm{~nm}) \& S i(30 \mathrm{~nm}) \mathrm{w} /$ heated glass effect. 


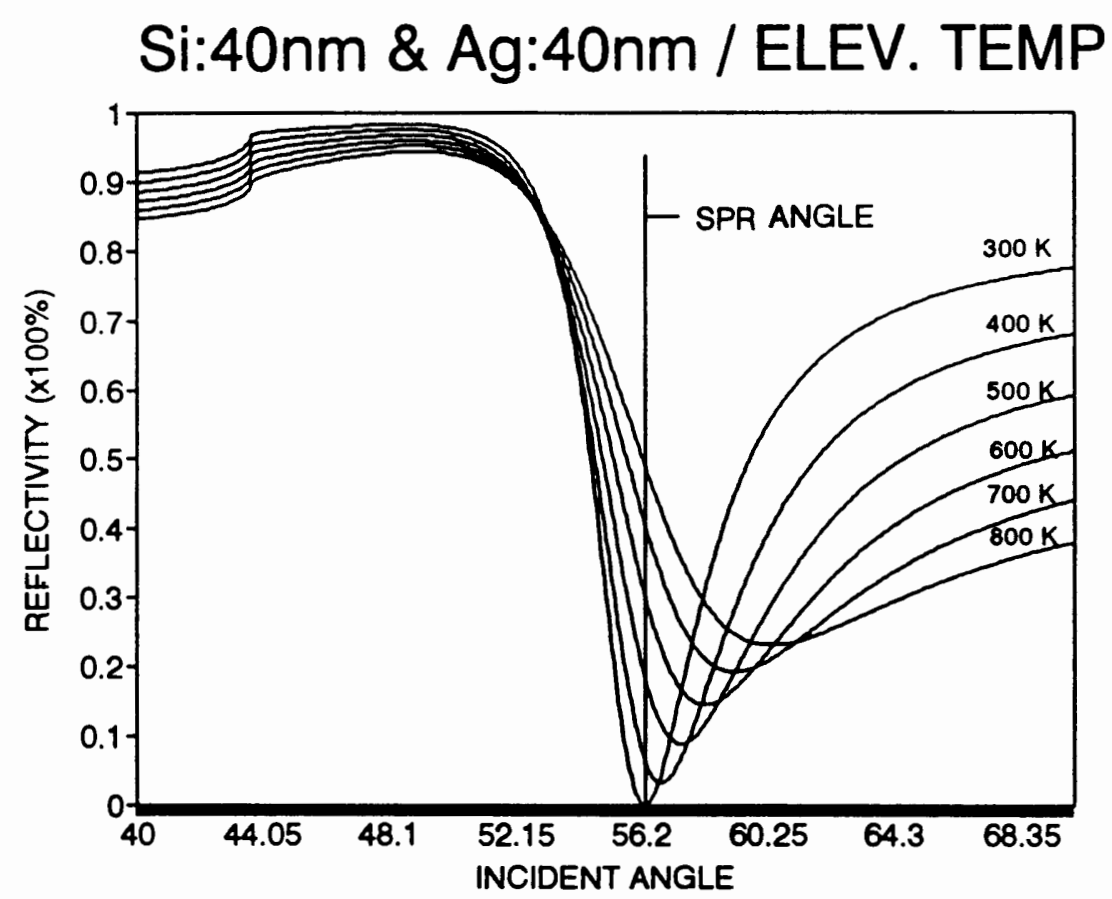

Figure 24. SPR reflectivity at elevated temperatures - Ag $(40 \mathrm{~nm}) \&$ Si $(40$ $\mathrm{nm})$. 


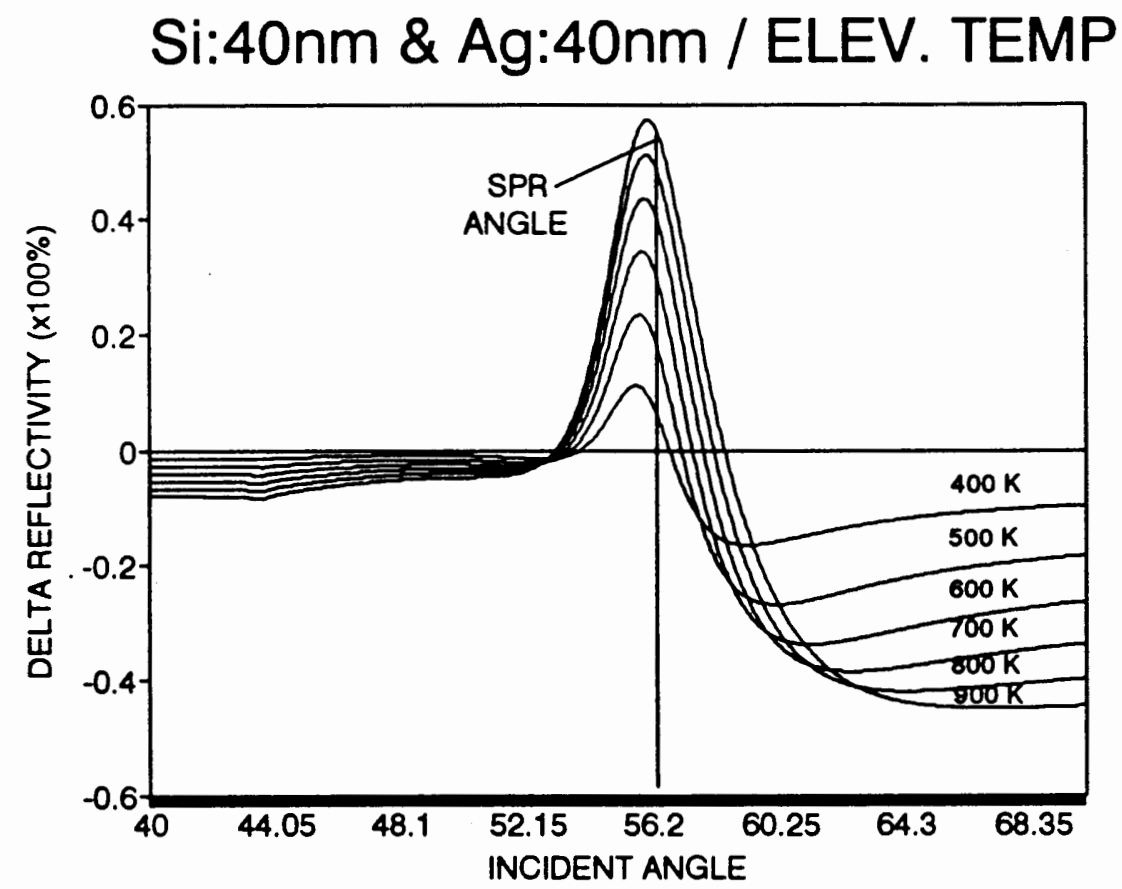

Figure 25. SPR $\triangle R$ at elevated temperatures - $A g(40 \mathrm{~nm}) \&$ Si $(40 \mathrm{~nm})$. 


\section{REFL. CHANGE AT SPECIFIED ANGLE}

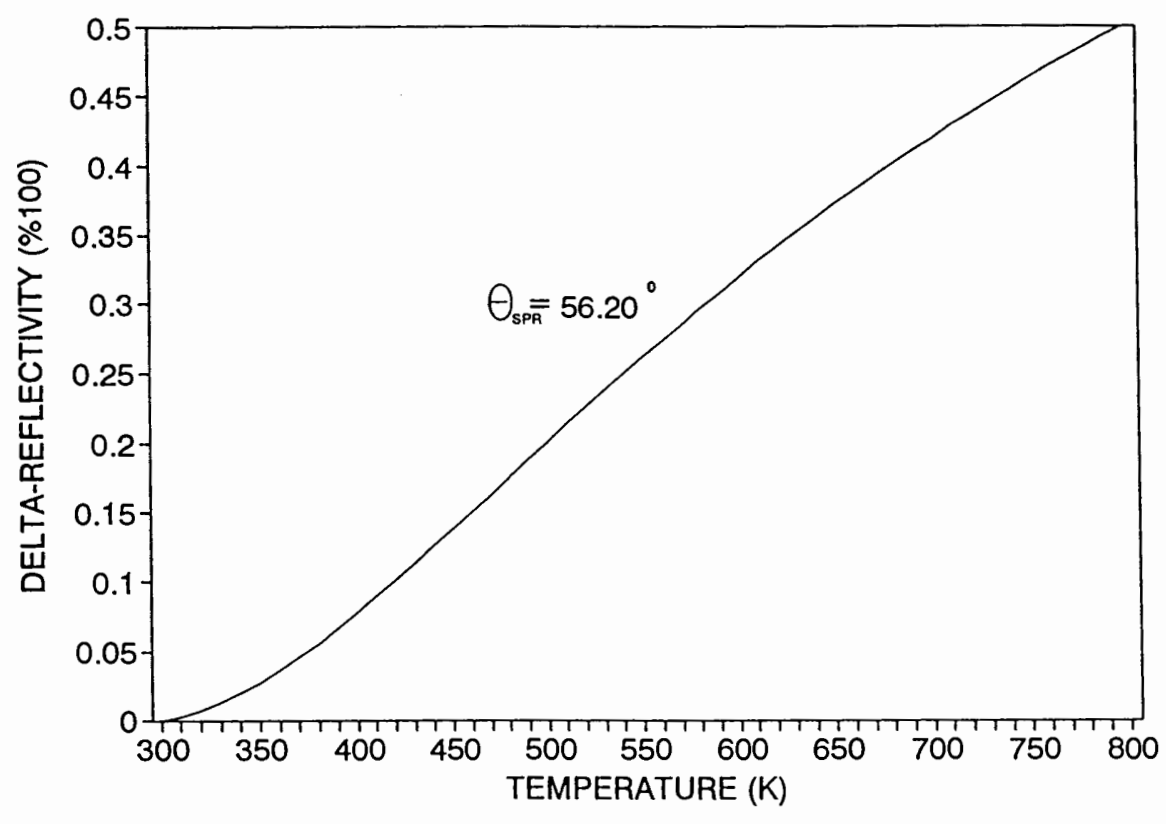

Figure 26. $\quad$ SPR $\triangle R$ at $S P R$ angle $\left(56.20^{\circ}\right)$ at elevated temperatures - Ag (40 nm) \& Si (40 nm) 


\section{Si:40nm \& Ag:40nm / ELEV. TEMP}

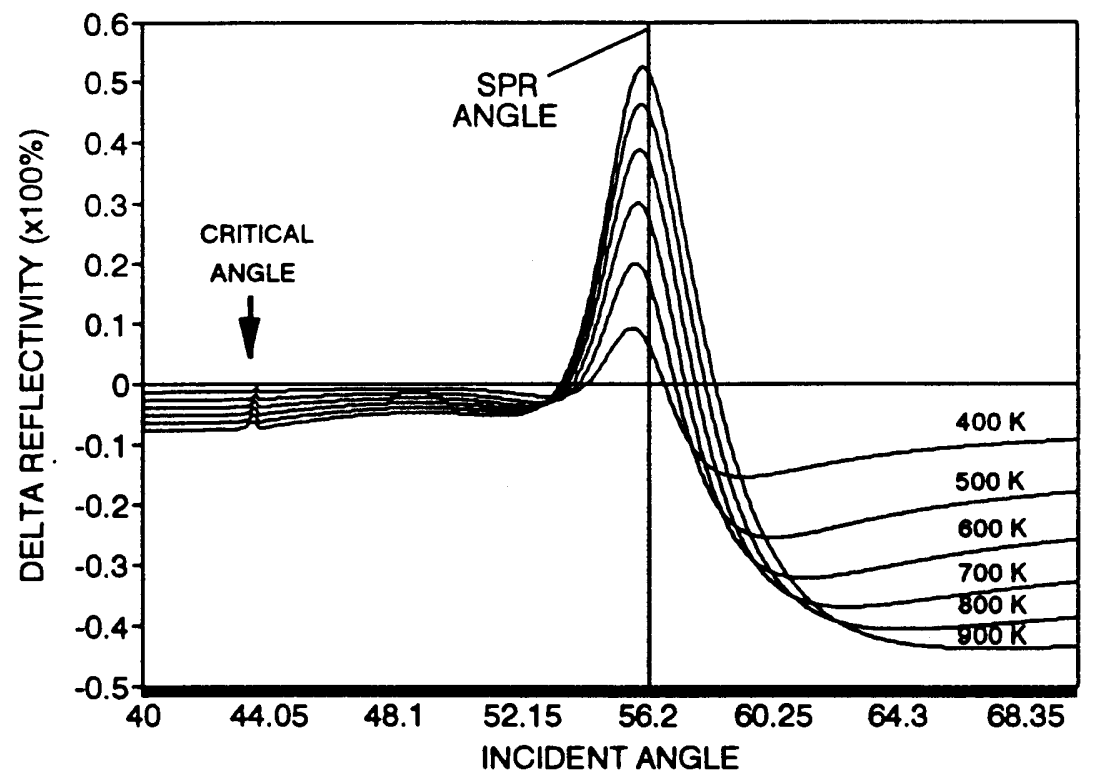

Figure 27. SPR $\triangle R$ at elevated temperatures - Ag $(40 \mathrm{~nm}) \& S i(40 \mathrm{~nm})$ $w /$ heated glass effect. 


\section{CHAPTER VI}

\section{DISCUSSION AND CONCLUSION}

Although our main motivation of this study is to investigate whether or not the SPR mechanism for the enhancement of photocurrent generation for an M-S junction can be maintained at elevated temperatures, we must admit that so far we have not come to a conclusive answer to the question. However, we believe that from our modeling of the SPR response for an M-S Junction at elevated temperatures, it is possible to draw some speculations on the issue as described below. Let us first give a brief summary of our modeling results.

From the SPR curves (Figs. 16, 20, and 24) at elevated temperatures, it was pointed out before that the dip curves become less shallow and broaden as temperature increases, this could imply that the collective excitation of the free electrons in the metal via the SPR mechanism becomes less efficient at high temperatures. In addition, we have also concluded from Figs. 17, 21, and 25 that if one were to observe the change in the SPR response for such a junction as the system is being heated, the maximum signal that one could obtain is to set the angle of the incident light very closely to the SPR dip angle.

Let us now comment on the possible implications of our modeling 
results on the quantum efficiency $(\mathrm{Q})$ of the $\mathrm{Ag}-\mathrm{Si}$ junction. To achieve a more conclusive answer for the effect on $Q$, one has also to know how the Schottky barrier height $\left(V_{b}\right)$ varies with temperature. Since $V_{b}$ could be given by the difference between the work function of the metal $(\phi)$ and the electron affinity of the semiconductor $(X),{ }^{20}$ one can hardly predict for a definite trend in the variation of $V_{b}$ with temperature since it is expected that both $\phi$ and $X$ in general become smaller as temperature increases. In fact, one can find in the literature, a number of investigations on $V_{b}-v s-T$ for different $M-S$ junctions in which both trends (increasing / decreasing) have been reported. For example, for an Al-nSi junction, $V_{b}$ has been reported to first decrease with the rise in temperature (from $450^{\circ} \mathrm{C}$ to $650^{\circ} \mathrm{C}$ ) and then increase from $650^{\circ} \mathrm{C}$ and up..$^{21}$ For an Au-nSi junction, however, it was reported earlier that the temperature dependence of $V_{b}$ is similar to that of the band gap of $\mathrm{Si}^{22}$ hence a monotonic decrease of $V_{b}$ with temperature. Very recently, in the study of an Al/AlGaAs junction, it is reported that depending on the doping, the junction with an n-type semiconductor will have $V_{b}$ decrease with increasing temperature all the way up to RT while that a $p$-type material will have $V_{b}$ almost constant up to $\mathrm{RT} .{ }^{23}$

Hence we can speculatively conclude that for those M-S junctions with $V_{b}$ remaining almost constant or increasing with increasing temperatures, the SPR mechanism for the enhancement of $Q$ will simply be less efficient whereas 
for systems with $V_{b}$ decreasing with temperature, the SPR mechanism may still work with large enhancement for $Q$ at elevated temperatures. We could not find a specific reference with regard to the variation of $V_{b}$ with temperature for an M-S system of Ag-Si such as the one in this thesis. But it is not unreasonable to expect the results should be qualitatively similar to that for Au-Si as reported in reference 22. Equally well, had we studied the Au-Si junction in our modeling work, we would expect similar qualitative results to be obtained as those we did for the Ag-Si case. If this is the case, it is likely that the SPR enhancement for $Q$ should sustain at high temperature environments for most of these noble metal-Si junctions.

In order to reach more solid conclusions concerning $Q$ enhancement an experimental setup which measures the SPR reflectance and $Q$ of the Ag-Si M$S$ junction would be necessary. Another interesting and feasible experimental setup might involve measuring the SPR effect and $Q$ due to very fast heating of the M-S system by a pulsed laser (into the UV), similar to the one reported in Ref. 2. The SPR response or $\Delta R$ could then be measured and checked against the present modeling results if the temperature rise due to pulsedheating could be calibrated. 


\section{REFERENCES}

1. J. D. Richards, Garabedian, C. Gonzalez, A. Knoesen, R.L. Smith, R Spencer, and S.D. Collins, Applied Optics 32 (16), 2901-2906 (1993).

2. S. Herminghaus and P. Leiderer, Appl. Phys. Lett. 51, 350-353 (1990).

3. 0.S. Heavens, Optical Properties of Thin Solid Films, (Dover, New York, (1991).

4. Keh-su Chang, Chien Chou, and Chin-hwa Lin, Applied Optics 32 (16), 2957-2962 (1993).

5. H. Raether, Surface Plasmons on Smooth and Rough Surfaces and on Gratings, Springer Tracts Modern Physics 111, 11 (1988).

6. C. Daboo, M.J. Baird, H.P. Hughes, N. Apsley, G. A. C. Jones, J. E. F. Frost, D.C. Peacock, and D. A. Ritchie, Thin Solid Films, 189, 27-38 (1990).

7. M.J. Cazca, C.C. Chang, and A.S. Karakashian, J. Appl. Phys. 66 (7), 3386-3391 (1989).

8. J. Derov, Y.Y. Teng and A.S. Karakashian, Physics Letters, 95A $(3,4)$, 197-200 (1983).

9. Malitson, I.H., Journal of the Optical Society of America 55 (10), 1205-1209 (1965).

10. Kikuo Ujihara, J. Appl. Phys. 43 (5), 2376 (1972).

11. David W. Lynch and W.R. Hunter, Optical Constants of Metals, (Academic, New York, 1985).

12. Piessens, R., E. de Doncker-Kapenga, C.W. Uberhuber, and D.K. Kahaner, (QUADPACK, Springer-Verlag, New York,1983). 
13. G. E. Jellison,Jr. ,F. A. Modine, C.W. White, R.F. Wood, and R.T. Young, Phys. Rev. Lett. , 46 (21), 1414-1417 (1981).

14. G.E. Jellison, Jr. and D.H. Lowndes, Appl. Phys. Lett. 41 (7), 594596 (1982).

15. G.E. Jellison, Jr. and H.H. Burke, J. Appl. Phys. 60 (2), 841-843, (1986).

16. O.S. Heavens, Optical Properties of Thin Solid Films, (Dover, New York, 1991).

17. W.R. Runyan, Silicon Semiconductor Technology, (McGraw-Hill, New York, 1965).

18. G. E. Jellison, Jr. and F. A. Modine, Appl. Phys. Lett. 27 (12), 74677468 (1983).

19. S. Herminghaus and P. Leiderer, Appl. Phys. Lett. 54 (2), 99-101 (1989).

20. E.H. Rhoderick and R.H. Williams, Metal-Semiconductor Contacts, (Clarendon, Oxford, 1988).

21. K. Chino, Solid State Electron 16, 119 (1973).

22. C.R. Crowell, S.M. Sze and W.G. Spitzer, Appl. Phys. Lett. 4 (91), (1964).

23. P. Revva, J.M. Langer, M. Missous and A.R. Peaker, J. Appl. Phys. 74 (1), 416-424 (1993). 


\section{APPENDIX}

MICROSOFT FORTRAN MODELING PROGRAM:

THIS PROGRAM FINDS REFLECTANCE VS INCIDENT ANGLE

C Program PROTO.FOR

IMPLICIT REAL*8 (A-H,O-Z)

COMPLEX * $16 \mathrm{Cl}, \mathrm{E} 1, \mathrm{E} 2, \mathrm{C} 1, \mathrm{C} 2, \mathrm{C} 3, \mathrm{CN} 1, \mathrm{R} 01, \mathrm{R} 12, \mathrm{CO}$

COMPLEX * 16 WN1Z,WN2Z,CE13,CE03,R23,R13,R03,RNO,RN2

PRINT* ,'PLEASE ENTER THE TEMPERATURE VALUES:'

READ* ${ }^{*}$ TSTART, TEND,TSTEP

PRINT* ,'PLEASE ENTER THE SILVER THICKNESS RANGE:'

READ* ,AGSTART, AGEND,AGSTEP

PRINT* ,'PLEASE ENTER THE SILICON THICKNESS RANGE:'

READ* ,SISTART, SIEND,SISTEP

PRINT* ,'PLEASE ENTER THE ANGLE SWEEP VALUES:'

READ* ,TOISTART, TOIEND, TOISTEP

C ***TEMPERATURE $(\mathrm{K}) * * *$

DO $1000 \mathrm{~T}=$ TSTART, TEND, TSTEP

C ***LAYER THICKNESS $(\mathrm{nm})^{* * *}$

DO 950 AGTHICK = AGSTART,AGEND, AGSTEP

DO 900 SITHICK = SISTART,SIEND,SISTEP

C ***EXPANSION FACTOR for SILVER ***

ALPHA $=1.87 E-5$

POISSON $=.3$

ALPHAP $=$ ALPHA $*(1 .+P O I S S O N) /(1 .-P O I S S O N)$

D1 = AGTHICK $*$ (1. + ALPHAP* $(T-300)$.

C ***EXPANSION FACTOR for SILICON***

ALPHA1 $=2.33 \mathrm{e}-6$

POISSON1 $=.25$

ALPHAP1 $=$ ALPHA $1 *(1 .+$ POISSON1)/(1.-POISSON1)

D2 $=$ SITHICK $*(1 .+$ ALPHAP $1 *(T-300)$.

C ***TITLE ON DATA FILE**

PRINT 10,T,D1,D2

WRITE $(7, *)$

WRITE $(7,10) \mathrm{T}, \mathrm{D} 1, \mathrm{D} 2$

10 FORMAT(F7.2,2x,F6.2,2x,F9.2)

C ***INCREMENT ANGLE*** 
APPENDIX

MICROSOFT FORTRAN MODELING PROGRAM:

THIS PROGRAM FINDS REFLECTANCE VS INCIDENT ANGLE

DO 800 TOI $=$ TOISTART, TOIEND, TOISTEP

$A=0$.

$B=1$.

$\mathrm{Cl}=\operatorname{DCMPLX}(\mathrm{A}, \mathrm{B})$

$\mathrm{PI}=3.14159265358979 \mathrm{DO}$

$\mathrm{TO}=\mathrm{TOI}{ }^{*} \mathrm{PI} / 180$.

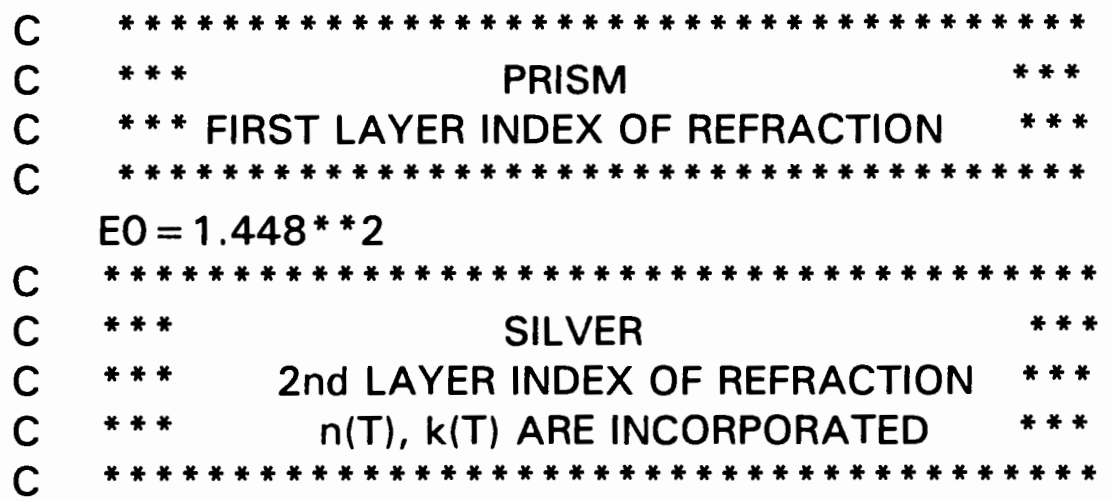

RNO1 $=(-2.6940057 \mathrm{e}-17) * \mathrm{t}^{*} * 5+(1.4011067 \mathrm{E}-13) * \mathrm{t}^{* *} 4+$

$+(-3.263565 \mathrm{E}-10) * \mathrm{t}^{*} * 3+(2.6774632 \mathrm{e}-7) * \mathrm{t}^{* *} 2+$

$+(.0010468868) * t-.074426718$

RK01 $=(-4.1111927 \mathrm{E}-18){ }^{*} \mathrm{t} *{ }^{*} 5+(2.6130184 \mathrm{E}-14) *{ }^{*} * 4+$

$+$

$(-1.8618681 E-11) * t^{* *} 3+(-2.4818215 E-7) *{ }^{*} * 2+(4.2517138 E-5) * t+$

$+7.8398805$

$\mathrm{E} 1 \mathrm{R}=\mathrm{RNO} 1 *$ * $2-\mathrm{RKO} 1 *$ *2

$\mathrm{E} 1 \mathrm{I}=2 .{ }^{*} \mathrm{RN} 01{ }^{*} \mathrm{RK} 01$

$E 1=D C M P L X(E 1 R, E 11)$

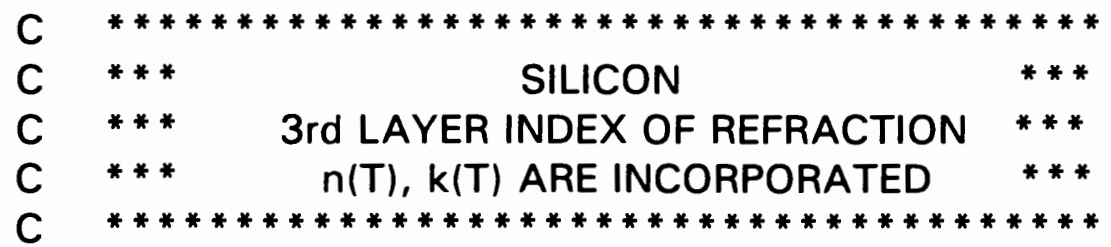

$\mathrm{RNO2}=(3.8834636 \mathrm{E}-27) * \mathrm{t}^{* *} 7+(-8.1051987 \mathrm{e}-23) * \mathrm{t}^{* *} 6+$

$+(3.1992203 \mathrm{E}-19) *{ }^{*} *{ }^{*}+(-5.272238 \mathrm{e}-16) *{ }^{*}{ }^{*} 4+$

$+(2.8385801 \mathrm{e}-13) * \mathrm{t} * * 3+(1.5024382 \mathrm{e}-10) * \mathrm{t}^{*} * 2+$

$+(.00021481613) * t+3.4500465$ 
APPENDIX

MICROSOFT FORTRAN MODELING PROGRAM:

THIS PROGRAM FINDS REFLECTANCE VS INCIDENT ANGLE

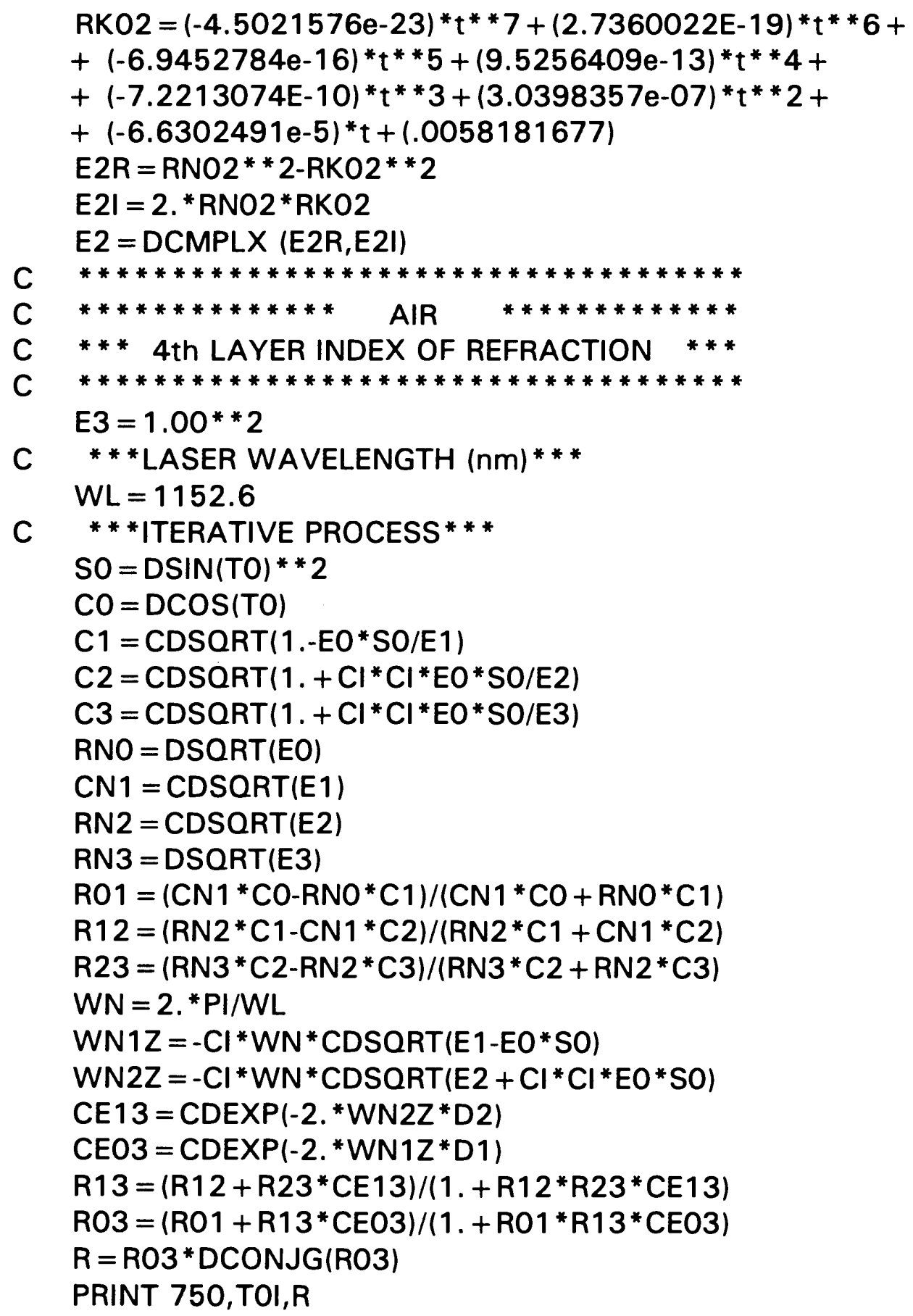


APPENDIX

MICROSOFT FORTRAN MODELING PROGRAM:

THIS PROGRAM FINDS REFLECTANCE VS INCIDENT ANGLE

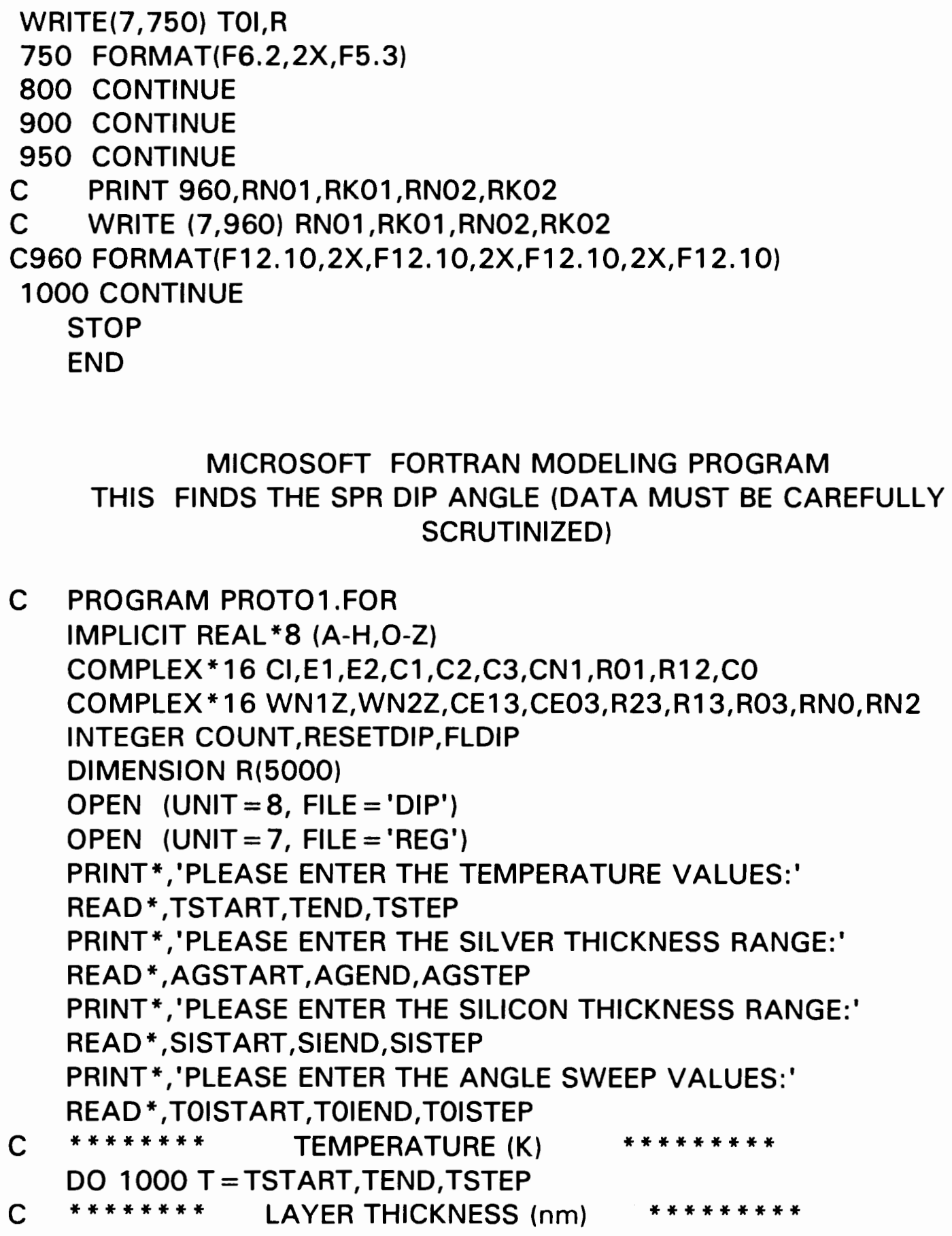


APPENDIX

MICROSOFT FORTRAN MODELING PROGRAM THIS FINDS THE SPR DIP ANGLE (DATA MUST BE CAREFULLY SCRUTINIZED)

DO 950 AGTHICK = AGSTART,AGEND, AGSTEP

DO 900 SITHICK = SISTART, SIEND, SISTEP

C ******** EXPANSION FACTOR for SILVER

ALPHA $=1.87 E-5$

POISSON $=.3$

ALPHAP $=$ ALPHA $*$ (1. +POISSON $) /(1 .-P O I S S O N)$

D1 = AGTHICK $*$ (1. + ALPHAP* $(T-300)$.

C ******** EXPANSION FACTOR for SILICON

ALPHA $1=2.33 e-6$

POISSON $1=.25$

ALPHAP $1=$ ALPHA $1 *(1 .+$ POISSON1)/(1.-POISSON 1$)$

D2 = SITHICK* $(1 .+$ ALPHAP1 * $(T-300)$.

C PRINT 10,T,D1,D2

C WRITE $(7, *)$

C WRITE $(7,10) \mathrm{T}, \mathrm{D} 1, \mathrm{D} 2$

10 FORMAT(F7.2,2x,F6.2,2x,F9.2)

C $\quad * * * * * * * \quad$ INCREMENT ANGLE

DO 800 TOI $=$ TOISTART, TOIEND, TOISTEP

COUNT $=$ COUNT +1

$A=0$.

$B=1$.

$\mathrm{Cl}=\operatorname{DCMPLX}(\mathrm{A}, \mathrm{B})$

$\mathrm{PI}=3.14159265358979 \mathrm{DO}$

TO $=$ TOI ${ }^{*} \mathrm{PI} / 180$.

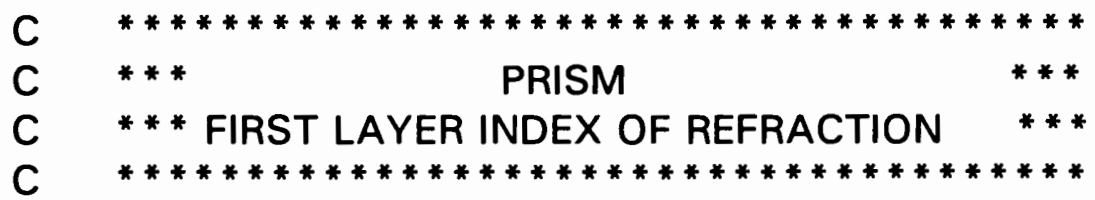

$E O=1.448 * * 2$

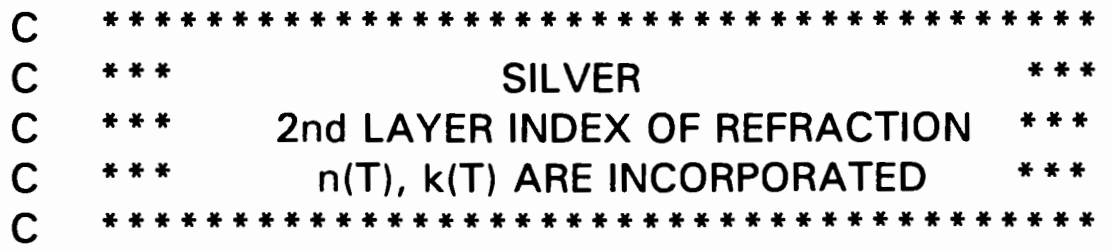

RNO1 $=(-2.6940057 \mathrm{e}-17)^{*} \mathrm{t} * * 5+(1.4011067 \mathrm{E}-13) * \mathrm{t} * * 4+$ 


\section{APPENDIX}

MICROSOFT FORTRAN MODELING PROGRAM

THIS FINDS THE SPR DIP ANGLE (DATA MUST BE CAREFULLY

SCRUTINIZED)

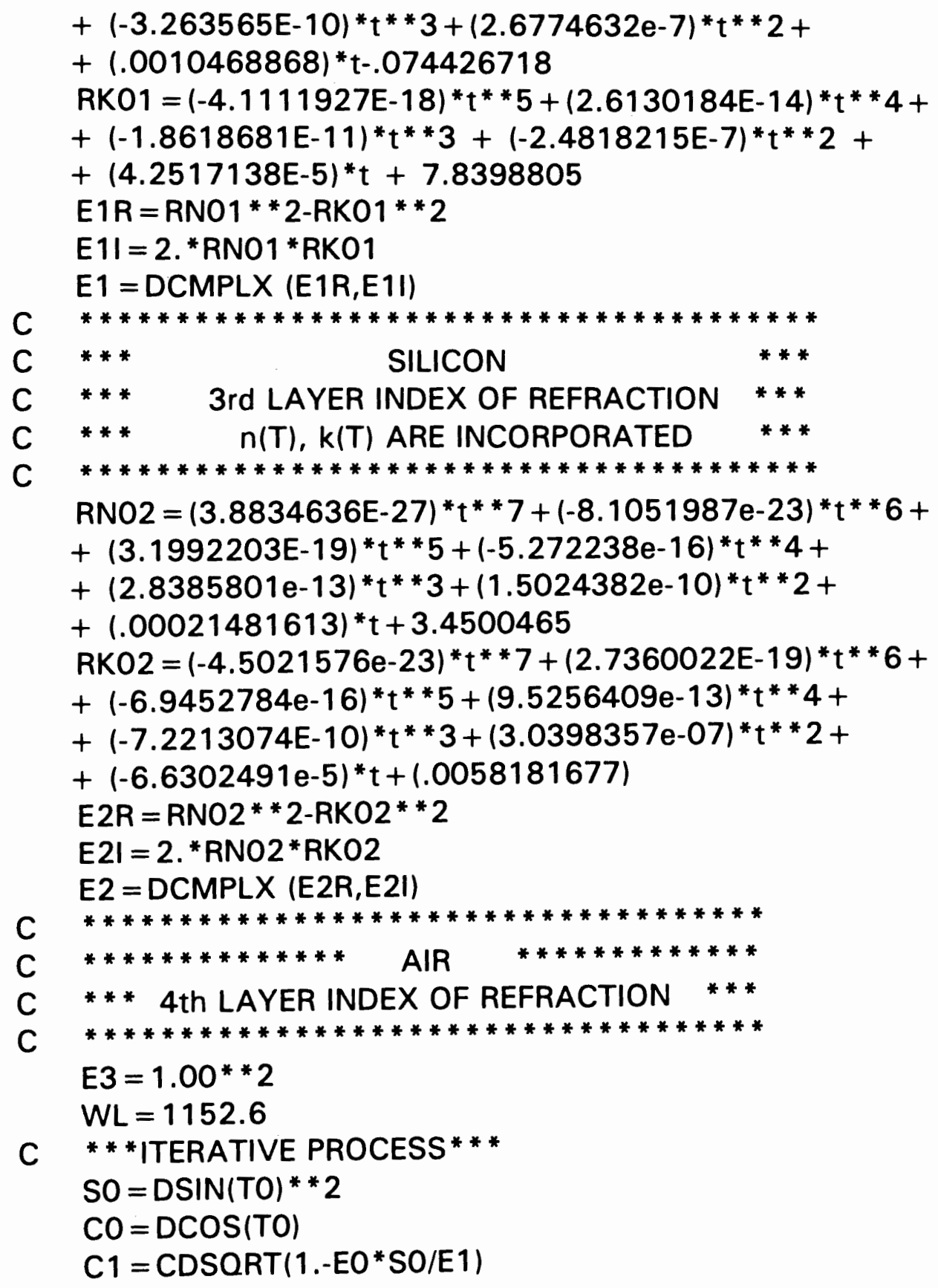




\section{APPENDIX}

\section{MICROSOFT FORTRAN MODELING PROGRAM \\ THIS FINDS THE SPR DIP ANGLE (DATA MUST BE CAREFULLY SCRUTINIZEDI}

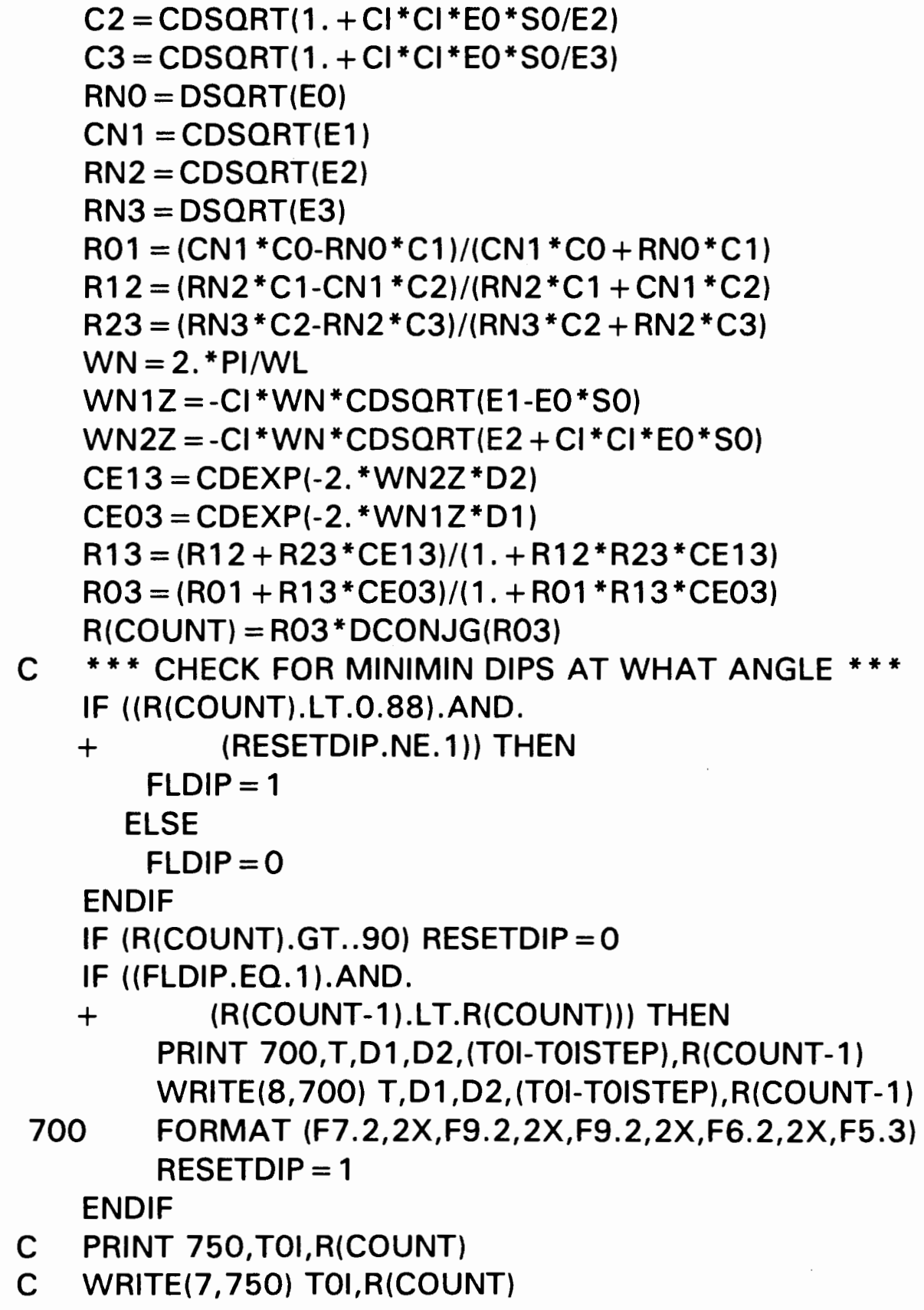




\section{APPENDIX}

\section{MICROSOFT FORTRAN MODELING PROGRAM}

THIS FINDS THE SPR DIP ANGLE (DATA MUST BE CAREFULLY SCRUTINIZED)

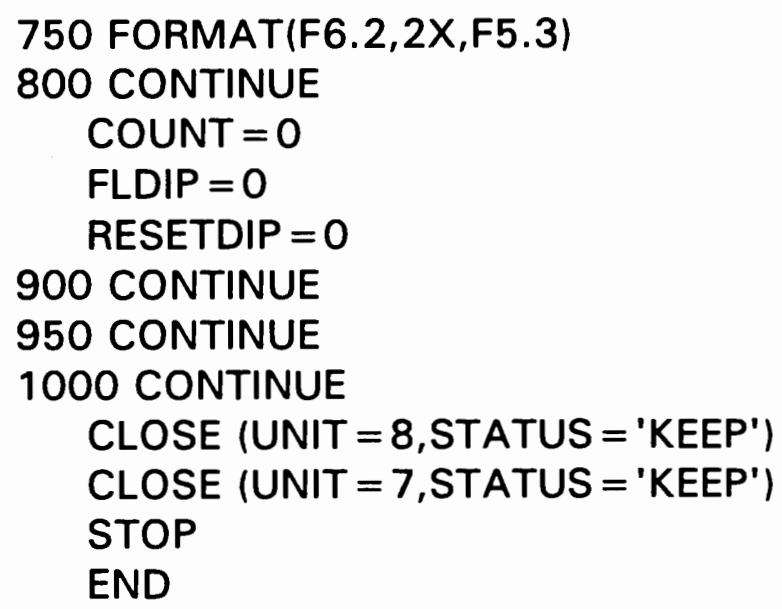

MICROSOFT FORTRAN SILICON $n(T), k(T)$ PROGRAM:

* CALCULATION OF OPTICAL COEFFICIENTS OF SI AT 1.15 micron *

IMPLICIT REAL*8 $(A-H, O-Z)$

DO $800 \mathrm{TM}=300 ., 1300 ., 100$.

$\mathrm{PI}=3.14159265358979 \mathrm{DO}$

$\mathrm{RN}=3.45+2.15 \mathrm{~d}-4 * \mathrm{TM}$

$\mathrm{WL}=1.1526$

$E P=124 . / 115$.

$E G=1.155-4.73 \mathrm{~d}-4 * \mathrm{tm}^{*} * 2 /(635 .+\mathrm{tm})$

$\mathrm{bc}=8.614 \mathrm{~d}-5$

e $11=e p-e g-b c * 212$.

$\mathrm{e} 12=\mathrm{ep}-\mathrm{eg}+\mathrm{bc} * 212$.

e21 $=$ ep-eg-bc $* 670$.

e22 $=$ ep-eg $+b c * 670$.

if(e11.gt.0.) then

a $11=0.504 *$ dsqrt $(e 11)+392 .{ }^{*}(e 11-0.0055) * * 2$ else $a 11=0$. 